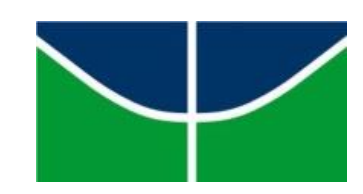

UNIVERSIDADE DE BRASÍLIA

FACULDADE DE CIÊNCIAS DA SAÚDE

DEPARTAMENTO DE ENFERMAGEM

MARINA SZERWINSK CAMARGOS

CONHECIMENTOS E ATITUDES PATERNAS FRENTE AO ALEITAMENTO MATERNO

BRASÍLIA 


\section{CONHECIMENTOS E ATITUDES PATERNAS FRENTE AO ALEITAMENTO MATERNO}

Trabalho de Conclusão de Curso (TCC) apresentado como requisito para aprovação na disciplina de Trabalho de Conclusão II, no curso de Graduação em Enfermagem, da Faculdade de Ciências da Saúde da Universidade de Brasília.

Orientadora: Msc. Mariana André Honorato Franzoi

BRASÍLIA 
CONHECIMENTOS E ATITUDES PATERNAS FRENTE AO ALEITAMENTO MATERNO

Trabalho de Conclusão de Curso (TCC) apresentado como requisito parcial para obtenção do grau de Bacharel em Enfermagem pelo curso de Graduação em Enfermagem da Faculdade de Ciências da Saúde da Universidade de Brasília do campus Darcy Ribeiro.

Aprovado em

\section{COMISSÃO EXAMINADORA}

Profa. Msc. Mariana André Honorato Franzoi

Universidade de Brasília - UNB

Orientadora - Presidente

Profa. Dra. Aline Oliveira Silveira

Universidade de Brasília - UNB

Membro Efetivo

Profa. Dra. Rita de Cássia Melão de Morais

Universidade de Brasília - UNB

Membro Efetivo

Profa. Dra. Gisele Martins

Universidade de Brasília - UNB

Membro Suplente 
Aos meus pais que sempre me apoiaram e me incentivaram a estudar e a querer crescer sempre. 


\section{AGRADECIMENTOS}

Em primeiro lugar, agradeço a Deus que me proporcionou saúde e força para superar as adversidades e conseguir concluir mais um ciclo importante de minha vida.

À minha professora e orientadora Mariana André Honorato Franzoi pela paciência e cuidado para com a conclusão deste trabalho.

Aos meus amigos de UnB Camila Medeiros, Mariana Terra, Victoria Silva, Isadora Ribeiro e Danielle Athaíde que tornaram mais doce e alegre minha jornada de 5 anos de UnB.

Aos professores do Departamento de Enfermagem pelos conhecimentos e aprendizagens que, com certeza, me tornarão uma profissional qualificada e consciente.

E por fim, à minha família que sempre me apoiou e me estimulou nos estudos, meu pai José Maria Rodrigues Camargos e minha mãe Sônia Maria Szerwinsk Camargos e meus irmãos: Guilherme, Rafael e Lidiane.

A todos que contribuíram com minha formação: muito obrigada! 
"Renda-se, como eu me rendi. Mergulhe no que você não conhece como eu mergulhei. Não se preocupe em entender, viver ultrapassa qualquer entendimento".

Clarice Lispector 


\section{RESUMO}

Introdução: A atitude dos pais no encorajamento a mãe atinge o contexto da assistência de saúde e promoção da saúde com reflexos futuros de boas práticas, assegurando integralidade do cuidado na tríade mãe-criança-pai. $O$ fato do pai possuir conhecimento, mesmo que mínimo sobre a amamentação, repercute na continuidade da prática de amamentar, ao passo que sua ausência torna o processo mais difícil. Estudos evidenciam cada vez mais a importância da participação paterna no incentivo e apoio à amamentação Objetivo: Identificar na literatura científica os conhecimentos e atitudes dos pais em relação ao aleitamento materno. Metodologia: Trata-se de uma revisão integrativa da literatura, que teve como pergunta norteadora: quais os conhecimentos e atitudes dos pais em relação à amamentação? Realizou-se busca online nas bases de dados Literatura Latino-Americana e do Caribe em Ciências da Saúde (LILACS), Medical Literature and Retrieval System On Line (MEDLINE/PUBMED) e Cummulative Index to Nursing and Allied Health Literature (CINAHL), a partir dos descritores "Father" $e$ "breast feending", combinados entre si por meio do operador booleano "AND”. Resultados: A amostra final foi composta por 16 artigos, que foram integrados em duas categorias temáticas, a saber: conhecimentos paternos em relação ao aleitamento materno: benefícios e desvantagens; e atitudes paternas frente à amamentação: enlaces entre desejos e impasses no apoio ao aleitamento materno. Conclusão: Os pais estão engajados e solícitos à promoção do aleitamento materno, todavia, alegam falta de conhecimento sobre vários aspectos em relação à amamentação. Além disso, é necessário avançar nas discussões de gênero em relação aos papeis do homem e da mulher no envolvimento e cuidados com bebê. Cabe aos profissionais de enfermagem desempenhar um papel mais incisivo de conscientização para a inclusão dos pais nos cuidados deste com a mulher e o bebê.

Descritores: Conhecimento; Amamentação; Pai. 


\section{LISTA DE QUADROS, TABELAS E GRÁFICOS}

Figura 1. Fluxograma dos artigos da revisão. Brasília, 2018.

Quadro 1. Motivos de exclusão dos estudos localizados na base de dados LILACS. Brasília, DF, 2018.

Quadro 2. Motivos de exclusão dos estudos localizados na base de dados MEDLINE. Brasília, DF, 2018.

Quadro 3. Motivos de exclusão dos estudos localizados na base de dados CINAHL. Brasília, DF, 2018.

Figura 2. Artigos da revisão por idiomas. Brasília, DF, 2018.

Figura 3. Distribuição do país, origem, dos artigos selecionados. Brasília, DF, 2018.

Gráfico 1. Gráfico dos artigos da revisão dispostos segundo ano e quantidade de publicações. Brasília, DF, 2018.

Tabela 1. Distribuição dos estudos segundo autor, ano de publicação, título, periódico e Qualis do periódico.

Tabela 2. Síntese de avaliação metodológica dos estudos inclusos na revisão. Brasília, DF, 2018. 


\section{SUMÁRIO}

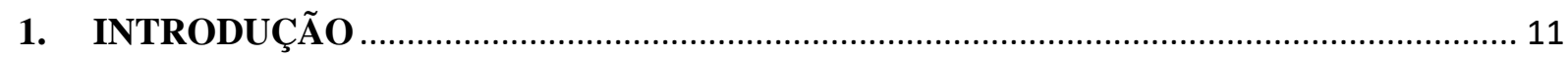

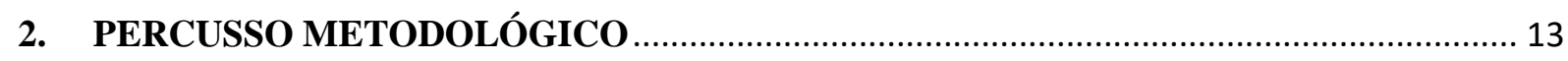

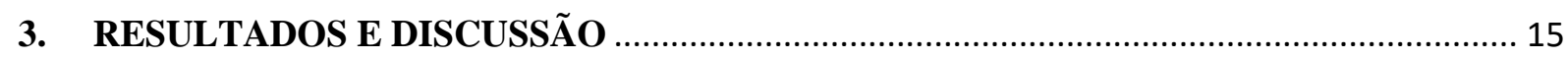

Figura 1. Fluxograma dos artigos da revisão. Brasília, 2018 ....................................................... 16

Quadro 1. Motivos de exclusão dos estudos localizados na base de dados LILACS.. Brasília, DF,

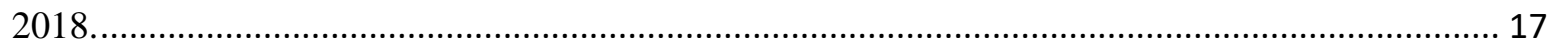

Quadro 2. Motivos de exclusão dos estudos localizados na base de dados MEDLINE. Brasília, DF, 2018

Quadro 3. Motivos de exclusão dos estudos localizados na base de dados CINAHL. Brasília, DF, 2018

Figura 2. Artigos da revisão por idiomas. Brasília, DF, 2018 ....................................................... 19

Figura 3. Distribuição do país, origem, dos artigos selecionados. Brasília, DF, 2018...................... 20

Gráfico 1. Gráfico dos artigos da revisão dispostos segundo ano e quantidade de publicações. Brasília, DF, 2018.

Tabela 1. Distribuição dos estudos segundo autor, ano de publicação, título, periódico e Qualis do periódico.

Tabela 2. Síntese de avaliação metodológica dos estudos inclusos na revisão. Brasília, DF, 2018. 24

1. Conhecimentos paternos em relação ao aleitamento materno: benefícios e desvantagens 31

2. Atitudes paternas frente à amamentação: enlaces entre desejos e impasses no apoio ao aleitamento materno.

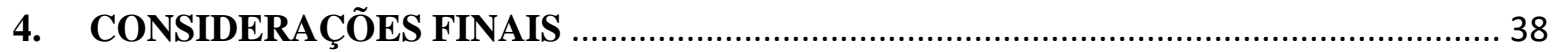

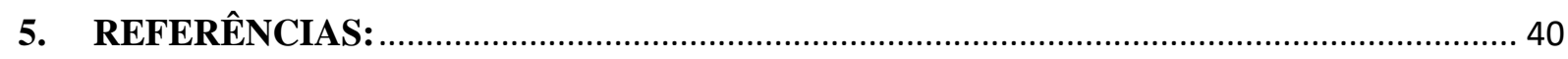




\section{INTRODUÇÃO}

A promoção do aleitamento materno faz parte de cuidados primários de saúde e contribui para a proteção da saúde da criança contra infecções, além de melhorar seu desenvolvimento físico e cognitivo a longo prazo, fortalecer o vínculo entre mãe e filho e envolver benefícios fisiológicos e psicossociais para a saúde da nutriz (OLIVEIRA et al, 2017). O Ministério da Saúde preconiza a amamentação até os 2 anos de vida da criança, sendo os 6 primeiros meses de aleitamento exclusivo. Quanto maior o tempo de amamentação, maiores os benefícios para mãe-bebê (BRASIL, 2015).

A amamentação, apesar de ser essencial para mãe e filho, não é um método fácil para se concretizar. Muitos fatores podem interferir positivamente e negativamente neste processo, sendo a família, em especial, o pai, potenciais apoiadores e facilitadores da amamentação. A presença do pai é fundamental para o fortalecimento deste processo (LIMA et al, 2017).

É notável a crescente participação dos pais ou companheiros interessados em participar de consultas de pré-natal, parto e puerpério, os quais até então eram ausentes e/ou excluídos desses momentos. Sua presença efetiva proporciona maior segurança e tranquilidade para a mulher enfrentar desafios inerentes ao período da gestação e puerpério (PETITO et al, 2015). Apesar disso, demorou-se demasiadamente para os homens desfrutarem de momentos únicos, como o nascimento dos filhos, e exercerem o papel de acompanhantes e cuidadores; apenas no ano de 2005 garantiu-se o direito de um acompanhante durante o trabalho de parto, parto e pós-parto, escolhido pela parturiente, devendo ser prontamente atendido pelos serviços de saúde do Sistema Único de Saúde - SUS, por meio da Lei no 11.108 de 7 de abril de 2005 (BRASIL, 2005).

Estudos evidenciam cada vez mais a importância da participação paterna no incentivo e apoio à amamentação. As puérperas percebem quão valiosa é a participação do companheiro no aleitamento materno evidenciado pelo incentivo e ajuda tanto para com elas, quanto para os filhos. O fato do pai possuir conhecimento, mesmo que mínimo sobre a amamentação, repercute na continuidade da prática de amamentar, ao passo que sua ausência, torna o processo mais difícil (FERRAZ et al, 2016). A atitude dos pais no encorajamento à mulher para iniciar e dar continuidade à amamentação atinge o contexto da assistência de saúde e promoção da saúde, com reflexos futuros de boas práticas, assegurando integralidade do 
cuidado na tríade mãe-criança e pai (BRASIL, 2018; SILVA; et al, 2012; SHERRIFF et al, 2014)

Considerando esta breve exposição sobre a participação paterna no processo de amamentação, propõe-se identificar estudos publicados sobre a temática na tentativa de elencar experiências e conhecimentos já concretizados para informar, atualizar e embasar futuras pesquisas voltadas ao tema, que desde então adianta-se carecer de maior visibilidade.

Desta forma, o presente estudo teve como objetivo principal identificar na literatura científica os conhecimentos e atitudes dos pais em relação ao aleitamento materno. 


\section{PERCUSSO METODOLÓGICO}

Trata-se de uma revisão integrativa da literatura, método de pesquisa que possibilita um recorte e acúmulo das principais pesquisas publicadas em relação a um tema específico, enriquecendo conclusões e apontando possíveis lacunas a serem preenchidas com novos estudos. A revisão integrativa torna-se relevante na área da saúde por sintetizar um grande volume de publicações e analisar criticamente as melhores evidências científicas disponíveis que possam embasar a prática de profissionais de saúde (MENDES; SILVEIRA; GALVÃO, 2008).

A revisão integrativa da literatura é composta por seis etapas, que foram observadas ao longo desta pesquisa, a saber: $1^{o}$ etapa- estabelecimento de hipótese ou questão de pesquisa: escolha e definição do tema, objetivos, palavras-chaves e tema pertencente à prática clínica; $2^{\circ}$ etapa- amostragem ou busca na literatura: selecionar critérios de inclusão e exclusão, uso de base de dados e distinção dos estudos; $3^{\circ}$ etapa- categorização dos estudos: captação das informações com organização e sumarização e formação do banco de dados; $4^{\circ}$ etapaavaliação dos estudos inclusos na revisão: aplicação de análises estatísticas, inclusão/exclusão de pesquisas e análise crítica dos estudos eleitos; $5^{\circ}$ etapa-interpretação dos resultados: discussão dos resultados, sugestões de recomendações e futuras pesquisas, e,

por fim, $\sigma^{o}$ etapa- síntese do conhecimento ou apresentação da revisão: resumo das evidências e elaboração de um documento escrito minuciosamente da revisão (MENDES $e t$ al, 2008).

Adotou-se a seguinte pergunta norteadora para o estudo: quais os conhecimentos e atitudes dos pais em relação ao aleitamento materno? Para responder ao questionamento, realizou-se um levantamento de publicações em periódicos por meio de busca on-line, no mês de abril de 2018, nas bases de dados Literatura Latino-Americana e do Caribe em Ciências da Saúde (LILACS), Medical Literature and Retrieval System On Line (MEDLINE/PUBMED) e Cummulative Index to Nursing and Allied Health Literature (CINAHL). Utilizaram-se os descritores "Father" e "breast feending", combinados entre si por meio do operador booleano "AND”. 
Após definição das bases e descritores, realizou-se a pré-seleção de artigos por meio da leitura de títulos e resumos, verificando-se a adequação quanto aos critérios de inclusão e de exclusão delimitados.

Os critérios de inclusão adotados compreenderam pesquisas originais de abordagem qualitativa e/ou quantitativa, publicadas no período de janeiro de 2010 a abril de 2018, escritas nos idiomas português, inglês e/ou espanhol, com resumo e texto disponíveis na íntegra, que abordassem os conhecimento e atitudes paternas frente à amamentação.

Os critérios de exclusão, por sua vez, consistiram em estudos com fuga ao tema, publicações na modalidade de cartas, revisão, artigos de opinião, notas prévias, reportagens, estudos duplicados, além de estudos que avaliassem o conhecimento e/ou atitudes do pai em relação à amamentação a partir da percepção de profissionais da saúde ou da mulher, nutriz ou gestante ou em contextos de intervenções e programas de educação em saúde.

Os artigos pré-selecionados foram submetidos à leitura na íntegra, sendo os artigos elegidos para a amostra final discriminados em planilha do Microsoft Office Excel 2010 para extração dos seguintes dados: autores, ano de publicação, nome da revista/periódico, objetivo, método e principais resultados de cada estudo. 


\section{RESULTADOS E DISCUSSÃO}

Identificaram-se um total de 910 artigos, os quais após serem filtrados por delimitação de ano, resultaram em 541 artigos. A partir da leitura de título e resumo, elegeram-se 23 artigos, dos quais excluíram-se 7 publicações após leitura na íntegra, sendo 2 por fuga ao tema, 3 por repetição e 2 por tipo de estudo totalizando uma amostra de 16 artigos (Figura 1).

Para organizar e analisar os dados dos artigos selecionados após todos os refinamentos, estruturou-se uma tabela a partir de instrumento elaborado pelas pesquisadoras que continha as seguintes informações: título, autor, periódico, objetivo, método, principais resultados e conclusões.

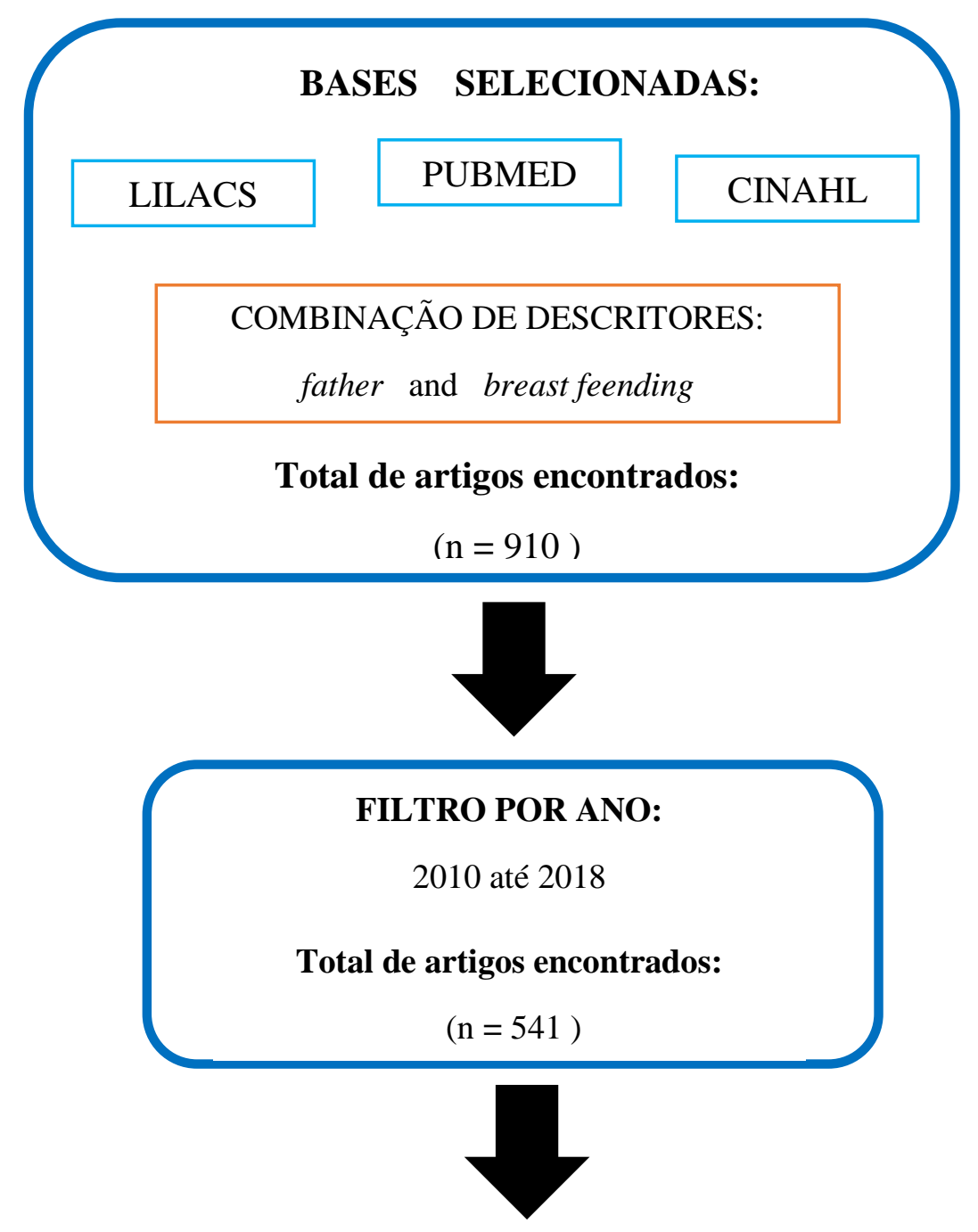




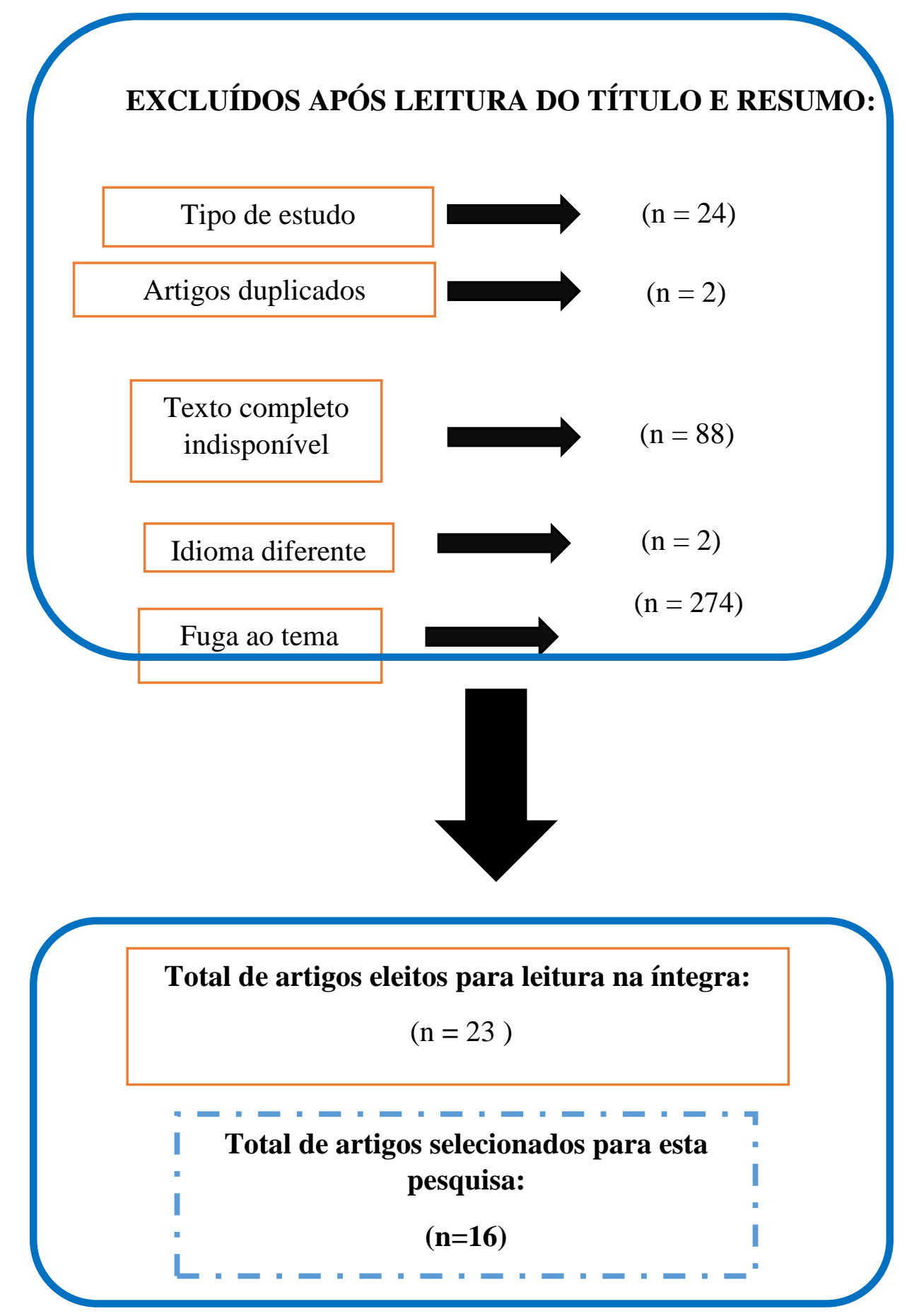

Figura 1. Fluxograma dos artigos da revisão. Brasília, 2018.

Os dados das três bases foram compilados em tabelas que representam, em maior detalhe, o fluxo de seleção dos artigos por base.

$\mathrm{Na}$ base LILACS, encontramos um total de 44 artigos. Ao aplicar o filtro para os anos de 2010-2018, o número caiu para 21 publicações. Na etapa de pré-seleção, feita a_partir da 
análise do título e do resumo, selecionou-se 5 artigos. Destes, apenas 3 entraram para análise deste trabalho, visto que 2 foram considerados como fuga ao tema após a leitura na íntegra

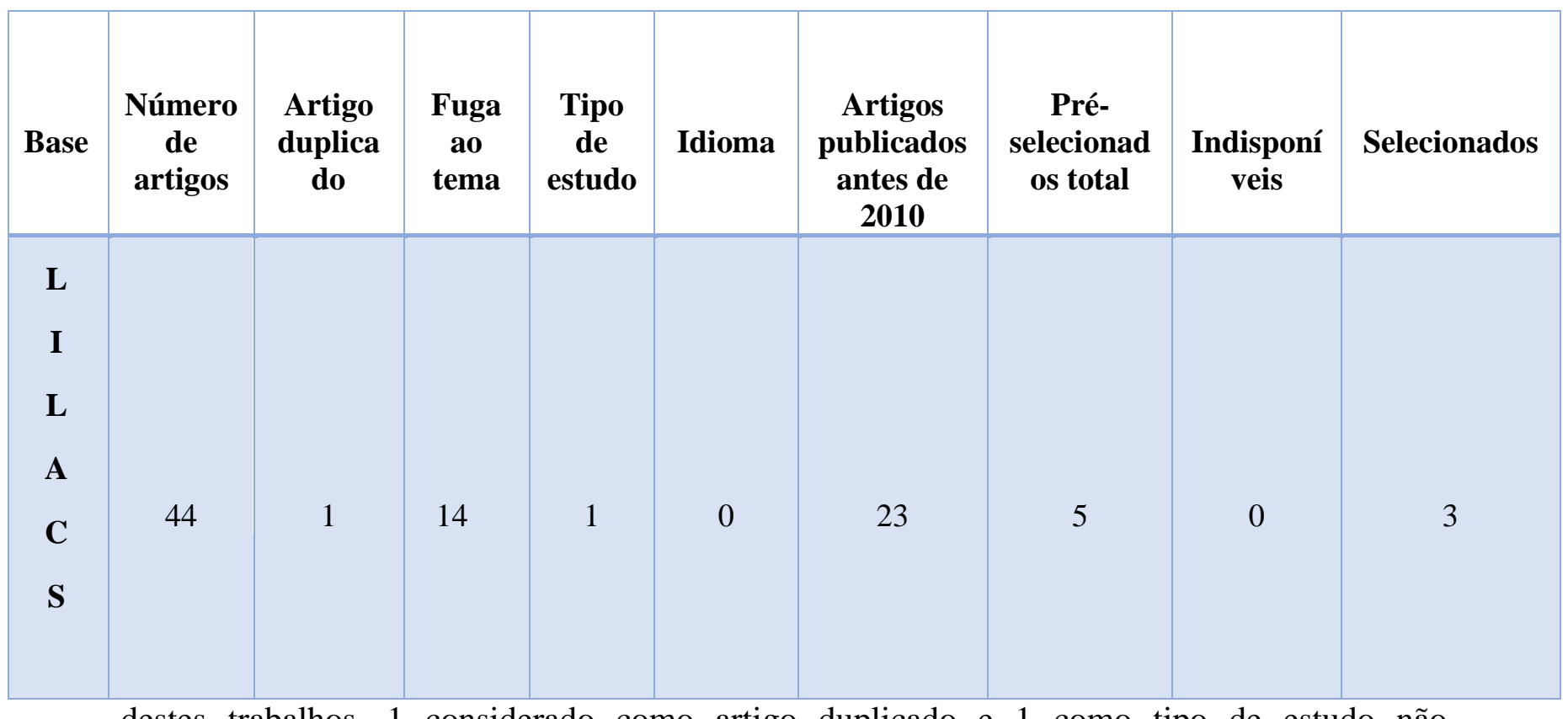

destes trabalhos, 1 considerado como artigo duplicado e 1 como tipo de estudo não comtemplado nesta pesquisa - revisão bibliográfica. (Quadro 1)

Quadro 1. Motivos de exclusão dos estudos localizados na base de dados LILACS.. Brasília, DF, 2018.

Quanto à base PUBMED, foram encontrados 570 artigos, que foram reduzidos para menos da metade, 222 publicações, ao aplicarmos o intervalo de tempo de 2010-2018. Desse universo, 192 publicações foram excluídas por fuga ao tema, 17 foram eliminados por se tratar de tipo de estudo, 5 por estarem indisponíveis na íntegra, 1 artigo estava duplicado e 2 repetidos na base CINAHL. A seleção final contemplou apenas 5 artigos.

Observa-se que o número de artigos enquadrados como fuga ao tema é demasiadamente alto. Enfatiza-se a necessidade de filtros mais sensíveis na busca avançada dessas plataformas de pesquisa, o que geraria dados mais realistas e contundentes com os objetivos de leitores, pesquisadores e profissionais da saúde. 


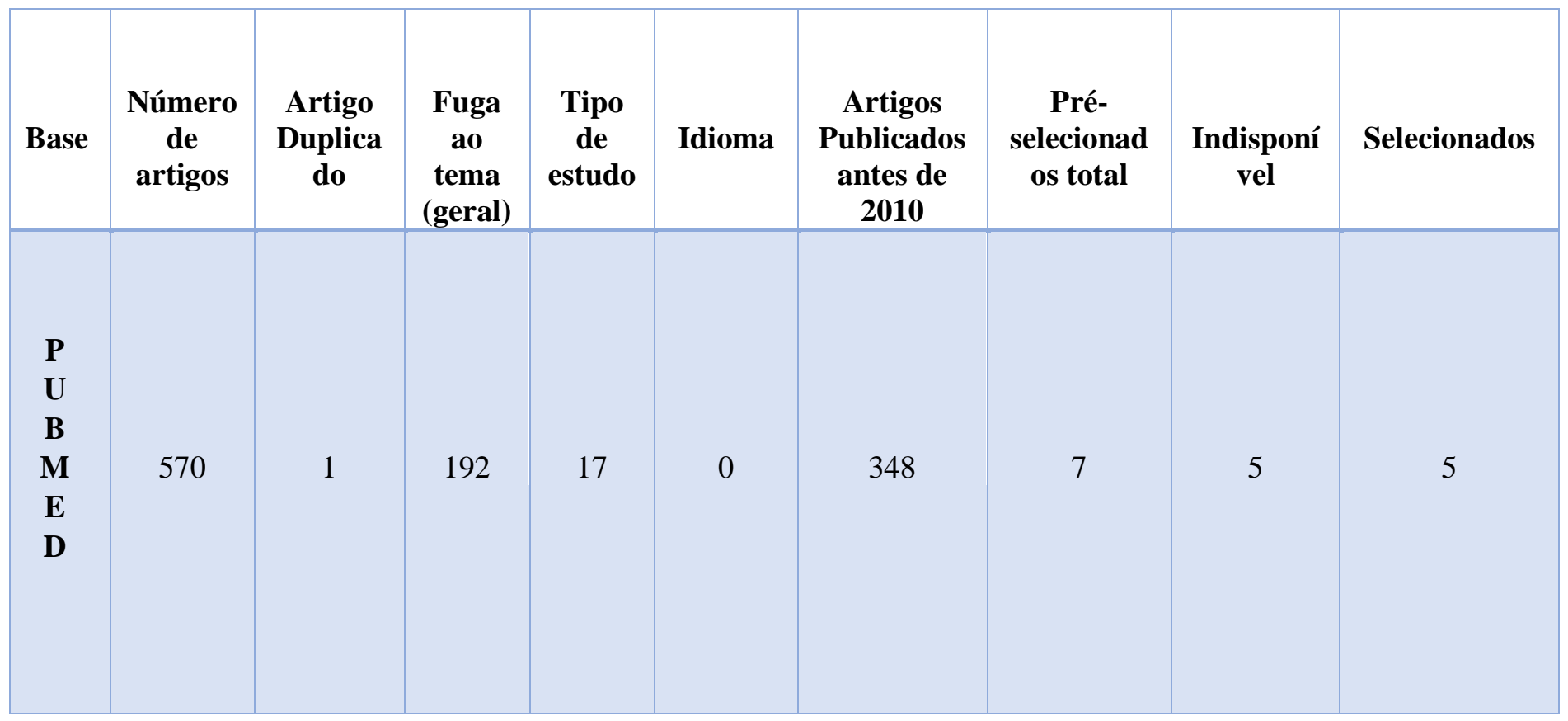

Quadro 2. Motivos de exclusão dos estudos localizados na base de dados MEDLINE. Brasília, DF, 2018.

Ao analisar os dados da plataforma CINAHL, percebe-se um dado interessante: do total de 126 artigos que resultaram da busca "father" + "breast feending", considerando o intervalo de tempo de 2010-2018, 83 publicações não foram validadas pelo quesito "Indisponível”, um número consideravelmente elevado, aproximadamente $65 \%$. O número de eliminação por "Fuga ao tema" também merece atenção, tendo em vista que 68 artigos foram eliminados por este critério. Ressalta-se ainda que esta plataforma foi a única que apresentou artigos em outras línguas com 1 artigo em língua coreana e outro em italiana. Para este trabalho considerou-se apenas publicações nos idiomas português, espanhol e inglês.

Dessa forma, do total de amostras, apenas 8 artigos foram selecionados para a análise final, o maior quantitativo de corpus no universo das três plataformas compreendidas nesta pesquisa.

Das três bases de pesquisa utilizadas neste trabalho, a CINAHL mostrou-se mais produtiva com relação a quantidade de artigos selecionados com a temática em questão, contudo, destaca-se que os números de artigos classificados como "Indisponível” é alarmante. O corpus desta pesquisa, por exemplo, poderia ter sido ampliado caso tivesse sido possível analisar na íntegra os artigos considerados como indisponíveis. 


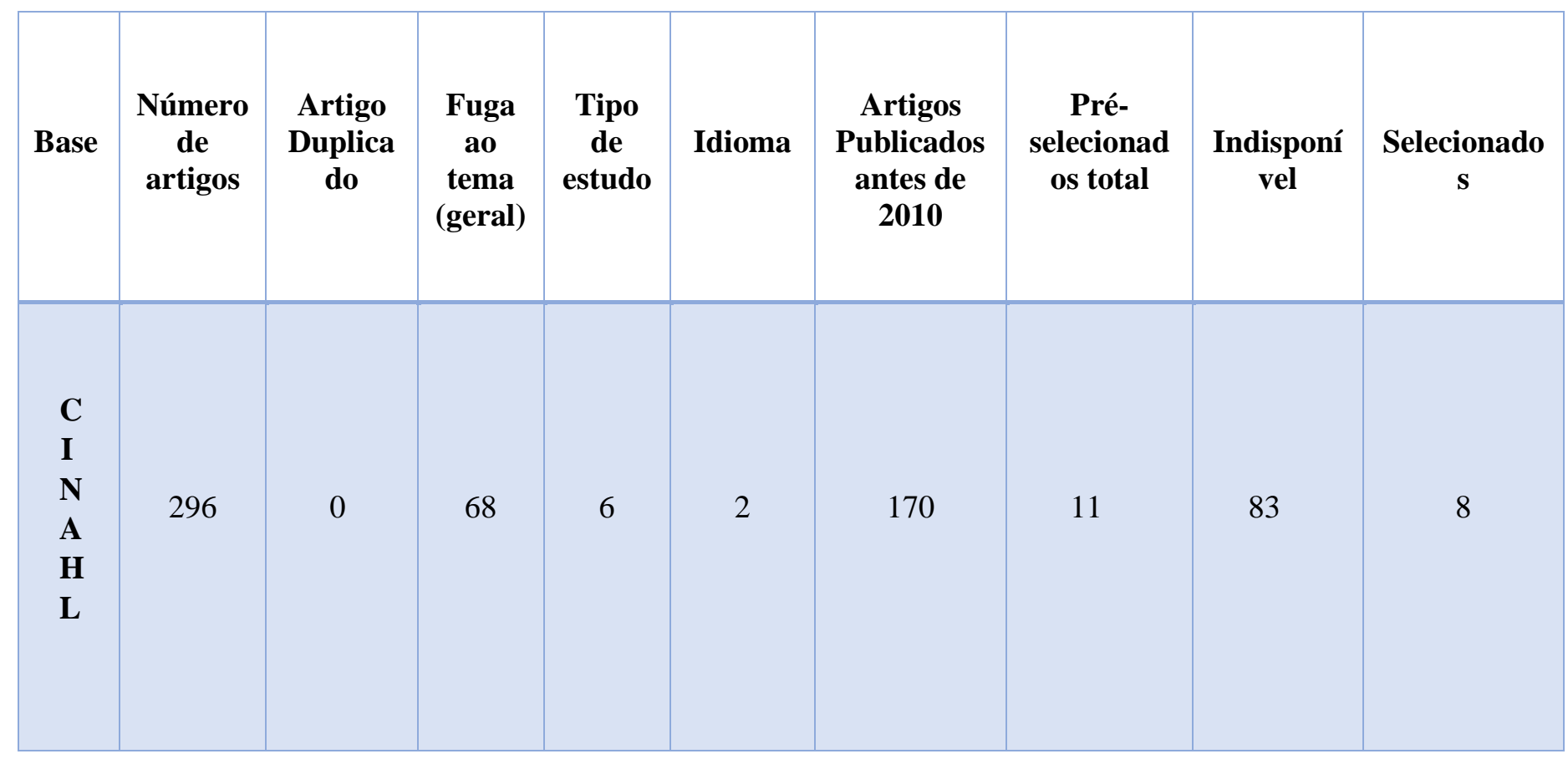

A plataforma LILACS foi a que apresentou a menor quantidade de artigos (44) e a PUBMED (570), em contrapartida, foi a que se destacou em números totais de resultado da busca.

Quadro 3. Motivos de exclusão dos estudos localizados na base de dados CINAHL. Brasília, DF, 2018.

Verifica-se a partir da Figura 2 abaixo, que o idioma inglês é predominante nas publicações, sendo apenas 4 pesquisas publicadas em língua portuguesa e nenhuma em língua espanhola, podendo remeter a seguinte reflexão: os pesquisadores de países hispanos publicam apenas em língua inglesa.

\section{Características dos artigos selecionados} quanto a idioma:

Idioma inglês: $(\mathrm{n}=13)$

Idioma espanhol: $(\mathrm{n}=0)$

Idioma português: $(n=3)$

Figura 2. Artigos da revisão por idiomas. Brasília, DF, 2018. 
Observa-se a partir da Figura 3 abaixo, que nesta revisão integrativa, o Brasil destacase com 5 publicações do total de 16 artigos. O valor apresenta-se por realçar o nosso país quanto a temática necessária e urgente para promover a promoção do aleitamento materno exclusivo. Pode-se esboçar a ideia de que o país desperta para futuras intervenções e tentativas de reverter o atual quadro em que se encontra na perspectiva do tema. Apesar de haver a maioria destes no idioma inglês, apenas encontrou-se um artigo dos Estados Unidos da América abordando a temática.

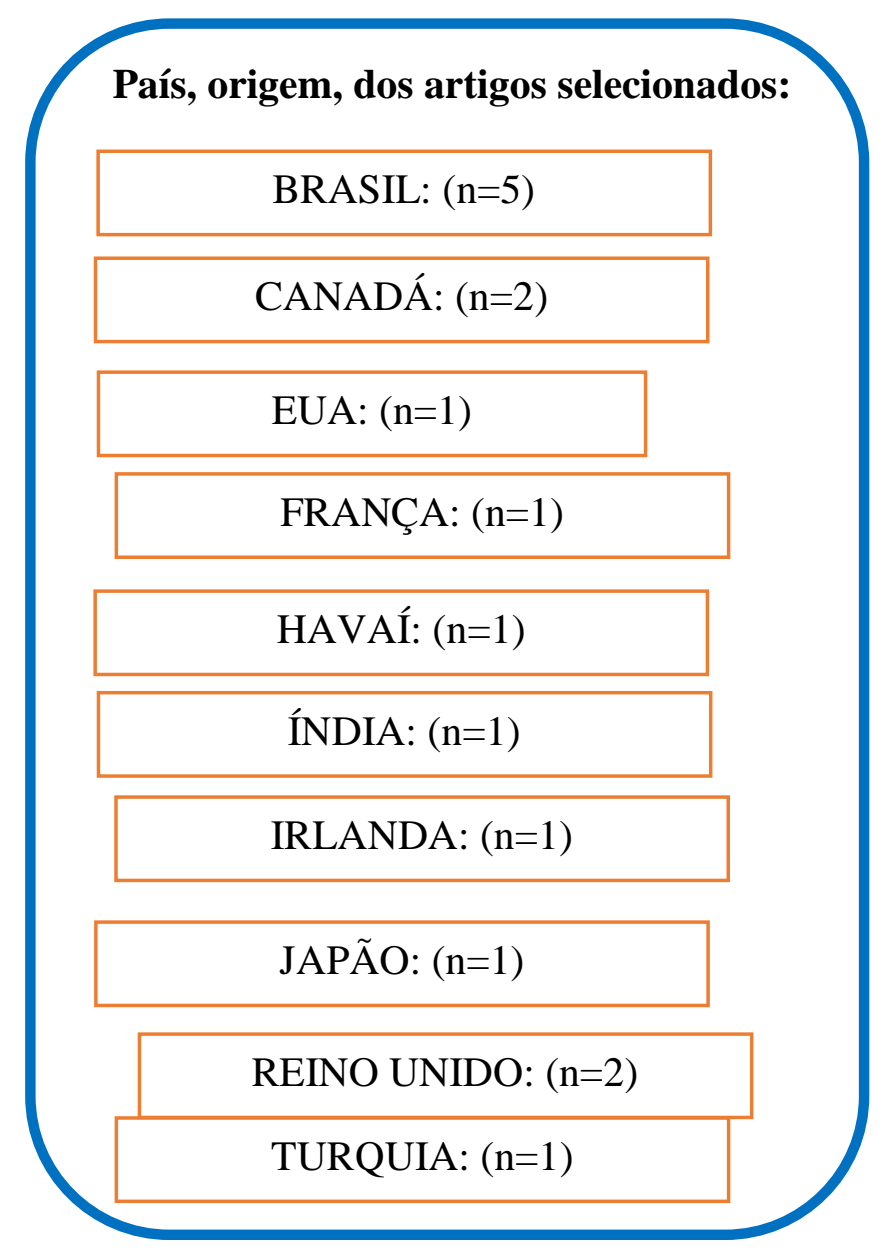

Figura 3. Distribuição do país, origem, dos artigos selecionados. Brasília, DF, 2018.

Para organizar e analisar os dados dos 23 artigos selecionados após todos os refinamentos, estruturou-se uma tabela a partir de instrumento elaborado pelas pesquisadoras que continha as seguintes informações: título, autor, periódico, objetivo, método, principais resultados e conclusões. 
Após a leitura na íntegra dos 23 artigos, excluíram-se 7 publicações, sendo 2 por fuga ao tema, 3 por repetição e 2 por tipo de estudo, totalizando uma amostra de 16 artigos.

Conforme o Gráfico 1 abaixo, os anos de 2010 e 2018 (abril de 2018) nota-se que houve apenas 1 publicação científica sobre o assunto em questão. Nos anos seguintes, 2011, 2012, 2014 e 2015 houve 2 publicações em cada ano. Destaca-se os anos de 2013 e 2016 como os mais produtivos, como a publicação de 3 artigos em cada ano, conforme pode-se verificar no gráfico 1. Contudo, no ano de 2017 não houve publicação neste amostra.

Esses resultados apontam que a temática necessita demasiadamente de mais pesquisas atualizadas a fim de reforçar a importância do pai em possuir conhecimento e atitude no contexto da amamentação (PIAZZALUNG e LAMONIER, 2011; SILVA et al, 2012)

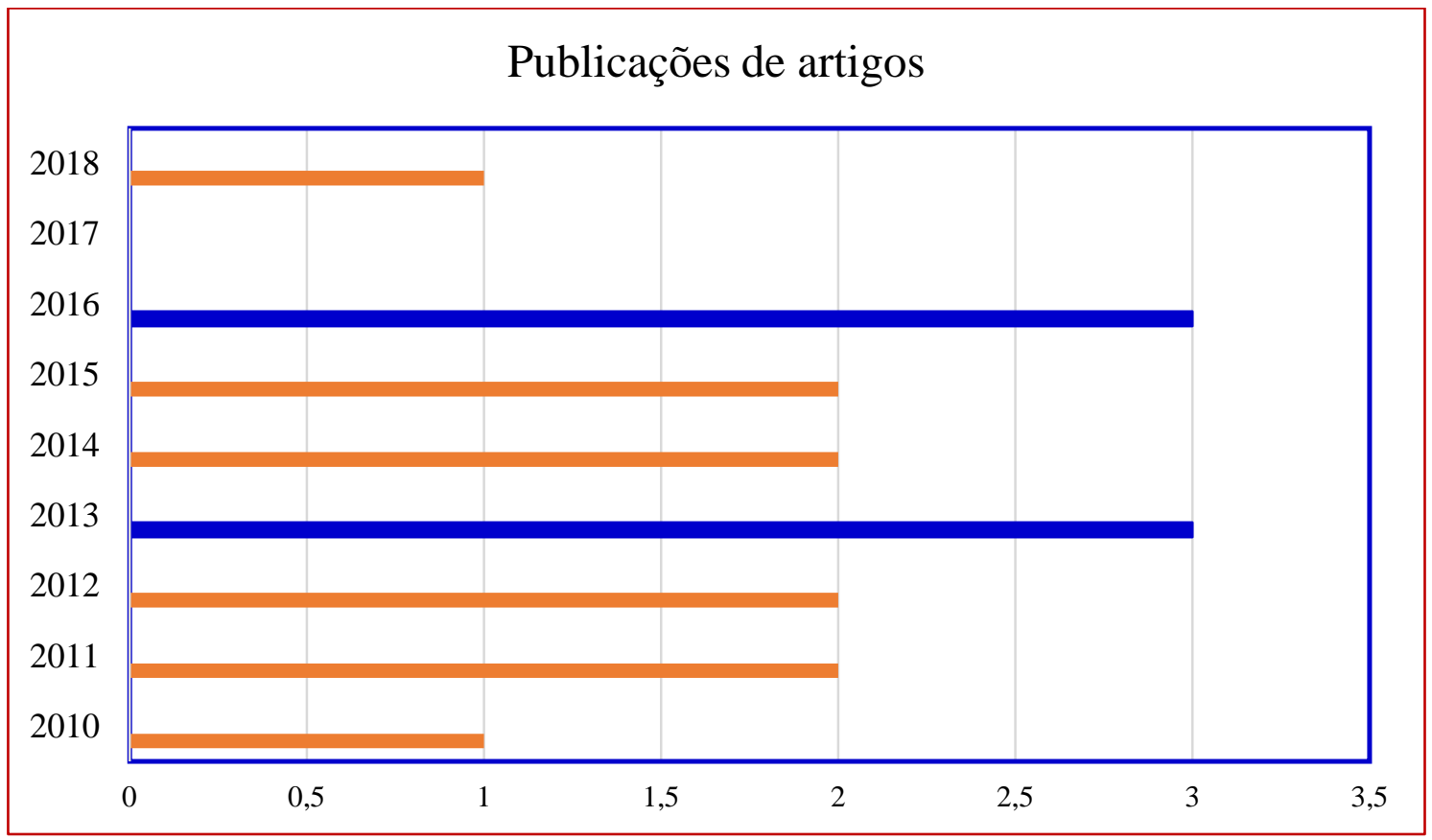

Gráfico 1. Gráfico dos artigos da revisão dispostos segundo ano e quantidade de publicações. Brasília, DF, 2018.

De acordo com a Tabela 1 abaixo, percebe-se uma variedade de periódicos nesta amostra, um total de 12 jornais/revistas científicas diferentes, com destaque para a revista Midwifery com 4 publicações. Esta variedade de periódicos reflete as várias possibilidades que a área da enfermagem pode encontrar para divulgação de suas publicações, incentivando os pesquisadores a contribuírem cientificamente com estudos na área de forma a divulgar e valorizar os conhecimentos oriundos de investigações. 
Analisando o Qualis dos periódicos na Tabela 1 abaixo, destaca-se o grande número de publicações em revistas e jornais com Qualis A na área de Enfermagem (06), o que demonstra qualidade e seriedade destas publicações. Verifica-se também (04) publicações com Qualis B e nenhuma publicação com Qualis C. Destaca-se também um número considerável do total dos periódicos que não apresentam área de enfermagem (06).

A Coordenação de Aperfeiçoamento de Pessoal de Nível Superior (Capes) possui cooperação científica tanto em âmbito nacional quanto internacional para facilitar a descrição científica do periódico em determinada área, considerada o título de qualidade que a pesquisa recebe. O Qualis hoje é considerado uma nova forma de reorientação dos periódicos. É o indicador de mérito científico, possibilitando financiamentos, tanto referentes aos periódicos quanto a programas de pós-graduação vinculados às revistas, acréscimos de títulos para bibliotecas e indexadores, busca de ferramentas científicas, elevar o nível de padrão de qualidade pelos editores e direcionamentos para leituras e pesquisas. O conceito de classificação de qualidade estende-se além dos já descritos, alcançando características verificadas em periódicos com grande circulação, indexação em bases importantes para a devida área de estudo e que aceite publicar amostras de diferentes áreas científicas (FRIGERI e MONTEIRO, 2015).

Tabela 1. Distribuição dos estudos segundo autor, ano de publicação, título, periódico e Qualis do periódico.

\begin{tabular}{|c|c|c|c|}
\hline AUTORES (ANO) & TÍTULO & PERIÓDICO & QUALIS \\
\hline $\begin{array}{c}\text { PAULA, } \text { et al } \\
\mathbf{( 2 0 1 0 )}\end{array}$ & $\begin{array}{c}\text { Aleitamento materno: } \\
\text { orientações, conhecimento e } \\
\text { participação do pai nesse } \\
\text { processo }\end{array}$ & $\begin{array}{c}\text { Revista Eletrônica de } \\
\text { Enfermagem }\end{array}$ & $\mathbf{B 1}$ \\
\hline $\begin{array}{c}\text { PIAZZALUNGA \& } \\
\text { LAMOUNIER } \\
(\mathbf{2 0 1 1})\end{array}$ & $\begin{array}{c}\text { O contexto atual do pai na } \\
\text { amamentação: } \\
\text { uma abordagem qualitativa }\end{array}$ & $\begin{array}{c}\text { Revista Médica de } \\
\text { Minas Gerais }\end{array}$ & $\mathbf{B 3}$ \\
\hline $\begin{array}{c}\text { REMPEL \& REMPEL } \\
(\mathbf{2 0 1 1})\end{array}$ & $\begin{array}{c}\text { The Breastfeeding Team: The } \\
\text { Role of Involved Fathers in the } \\
\text { Breastfeeding Family }\end{array}$ & $\begin{array}{c}\text { Journal of Human } \\
\text { Lactation }\end{array}$ & $\begin{array}{c}\text { Não tem área de } \\
\text { enfermagem }\end{array}$ \\
\hline
\end{tabular}




\begin{tabular}{|c|c|c|c|}
\hline $\begin{array}{l}\text { MITCHELL-BOX \& } \\
\text { BRAUN } \\
(\mathbf{2 0 1 2}) \\
\end{array}$ & $\begin{array}{l}\text { Fathers' Thoughts on } \\
\text { Breastfeeding and Implications } \\
\text { for a Theory-Based Intervention }\end{array}$ & $\begin{array}{l}\text { Journal of Obstetric, } \\
\text { Gynecologic, \& } \\
\text { Neonatal Nursing }\end{array}$ & $\begin{array}{l}\text { Não tem área de } \\
\text { enfermagem }\end{array}$ \\
\hline $\begin{array}{l}\text { CHEZEM } \\
\text { (2012) }\end{array}$ & $\begin{array}{l}\text { Breastfeeding Attitudes Among } \\
\text { Couples Planning Exclusive } \\
\text { Breastfeeding or Mixed Feeding }\end{array}$ & Breastfeeding Medicine & $\begin{array}{l}\text { Não tem área de } \\
\text { enfermagem }\end{array}$ \\
\hline $\begin{array}{l}\text { JACOB } \\
\& \text { SUJATHA } \\
\\
\text { (2013) }\end{array}$ & $\begin{array}{l}\text { An Exploratory Study on } \\
\text { Knowledge and Attitude of } \\
\text { Fathers Towards Breastfeeding } \\
\text { in Selected Hospitals at } \\
\text { Mangalore }\end{array}$ & $\begin{array}{l}\text { Journal of Nursing } \\
\text { Education }\end{array}$ & $\begin{array}{l}\text { Não tem área de } \\
\text { enfermagem }\end{array}$ \\
\hline $\begin{array}{l}\text { TAS-PINAR, et al } \\
\text { (2013) }\end{array}$ & $\begin{array}{c}\text { Fathers' knowledge about and } \\
\text { attitudes towards breast feeding } \\
\text { in Manisa, Turkey }\end{array}$ & Midwifery & A1 \\
\hline $\begin{array}{l}\text { ITO et al } \\
(\mathbf{2 0 1 3})\end{array}$ & $\begin{array}{c}\text { Is Paternal Infant Care } \\
\text { Associated with Breastfeeding? A } \\
\text { Population-Based Study in Japan }\end{array}$ & $\begin{array}{l}\text { Journal of human } \\
\text { lactation }\end{array}$ & A1 \\
\hline $\begin{array}{c}\text { BROWN \& DAVIES } \\
(\mathbf{2 0 1 4 )}\end{array}$ & $\begin{array}{l}\text { Fathers' experiences of } \\
\text { supporting breastfeeding: } \\
\text { challenges for breastfeeding } \\
\text { promotion and education }\end{array}$ & $\begin{array}{l}\text { Maternal and Child } \\
\text { Nutrition }\end{array}$ & $\begin{array}{l}\text { Não tem área de } \\
\text { enfermagem }\end{array}$ \\
\hline $\begin{array}{l}\text { LACERDA, et al } \\
\quad(\mathbf{2 0 1 4 )}\end{array}$ & $\begin{array}{l}\text { Adolescent fathers: Knowledge of } \\
\text { and involvement in the breast } \\
\text { feeding process in Brazil }\end{array}$ & Midwifery & A1 \\
\hline $\begin{array}{l}\text { EMMOTT \& MACE } \\
\qquad(\mathbf{2 0 1 5})\end{array}$ & $\begin{array}{c}\text { Practical Support from Fathers } \\
\text { and Grandmothers Is Associated } \\
\text { with Lower Levels of } \\
\text { Breastfeeding in the UK } \\
\text { Millennium Cohort Study }\end{array}$ & PLoS One & $\begin{array}{l}\text { Não tem área de } \\
\text { enfermagem }\end{array}$ \\
\hline $\begin{array}{l}\text { MATOS, et al } \\
\text { (2015) }\end{array}$ & $\begin{array}{c}\text { Perception and support given by } \\
\text { father in maintenance of } \\
\text { breastfeeding }\end{array}$ & $\begin{array}{l}\text { Revista de Enfermagem } \\
\text { UFPE on line }\end{array}$ & B2 \\
\hline $\begin{array}{l}\text { AZEVEDO, et al } \\
\text { (2016) }\end{array}$ & $\begin{array}{c}\text { Knowledge of man about } \\
\text { breastfeeding }\end{array}$ & Acta Scientiarum & B2 \\
\hline DENOUAL, et al (2016) & $\begin{array}{l}\text { Father's role in supporting } \\
\text { breastfeeding of preterm infants } \\
\text { in the neonatal intensive care }\end{array}$ & BMJ ope & A2 \\
\hline
\end{tabular}




\begin{tabular}{|c|c|c|c|}
\hline & unit: a qualitative study & A1 \\
\hline $\begin{array}{c}\text { BENNETT, et al } \\
(\mathbf{2 0 1 6 )}\end{array}$ & $\begin{array}{c}\text { Views of fathers in Ireland on the } \\
\text { experience and challenges of } \\
\text { having a breast-feeding partner }\end{array}$ & Midwifery & $\mathbf{A 1}$ \\
\hline $\begin{array}{c}\text { MONTIGNY, et al } \\
(\mathbf{2 0 1 8})\end{array}$ & $\begin{array}{c}\text { The role of fathers during } \\
\text { breastfeeding }\end{array}$ & Midwifery & . \\
\hline
\end{tabular}

Ao analisar a metodologia empregada nos artigos selecionados para esta pesquisa, verificou-se que pesquisas de abordagem qualitativa se destacaram por compreenderem 10 publicações em relação a 6 estudos de abordagem quantitativa (Tabela 2).

O objetivo ético e social de uma pesquisa qualitativa é abranger aspectos transparentes sobre a temática em análise, com finalidades predispostas para que e para quem receberá o conhecimento, alvejando impactos positivos para a sociedade. Este tipo de metodologia enxerga o invisível e a subjetividade, expande a visão da enfermagem considerando vários fatores interligados a saúde do ser humano. É um método eficaz e eficiente para os profissionais da saúde por ajudar a entender complexidades únicas que são chaves para o cuidado individualizado (LACERDA e LABRONICI, 2011).

Tabela 2. Síntese de avaliação metodológica dos estudos inclusos na revisão. Brasília, DF, 2018.

\begin{tabular}{|c|c|c|c|c|c|}
\hline $\begin{array}{l}\text { Autores } \\
\text { (ano) }\end{array}$ & Objetivos & $\begin{array}{l}\text { Abordagem } \\
\text { Metodológica }\end{array}$ & Metodologia & Principais resultados & Base \\
\hline $\begin{array}{l}\text { PAULA, et al } \\
(\mathbf{2 0 1 0})\end{array}$ & $\begin{array}{l}\text { Investigar o } \\
\text { conhecimento } \\
\text { do pai acerca do } \\
\text { aleitamento } \\
\text { materno, } \\
\text { orientações } \\
\text { oferecidas a ele } \\
\text { durante o pré- } \\
\text { natal e analisar a } \\
\text { sua participação } \\
\text { nesse processo. }\end{array}$ & $\begin{array}{l}\text { Estudo descritivo de } \\
\text { abordagem } \\
\text { qualitativa, realizado } \\
\text { em Goiânia/Goiás. A } \\
\text { coleta de dados foi } \\
\text { realizada com } 9 \text { pais. } \\
\text { Entrevista utilizando- } \\
\text { se roteiro semi- } \\
\text { estruturado. }\end{array}$ & Qualitativa & $\begin{array}{l}\text { O pai não está envolvido no } \\
\text { processo de amamentação. A } \\
\text { maioria dos entrevistados } \\
\text { desejava ser pai e que seus } \\
\text { filhos fossem amamentados, } \\
\text { reconhecem os benefícios do } \\
\text { aleitamento para a criança, } \\
\text { mas desconhecem os } \\
\text { benefícios da amamentação } \\
\text { para a mãe. Os dados } \\
\text { mostram que não há uma }\end{array}$ & $\begin{array}{l}\text { L } \\
\text { I } \\
\text { L } \\
\text { A } \\
\text { C } \\
\text { S }\end{array}$ \\
\hline
\end{tabular}




\begin{tabular}{|c|c|c|c|c|c|}
\hline & & & & $\begin{array}{l}\text { participação ativa desses na } \\
\text { amamentação. }\end{array}$ & \\
\hline $\begin{array}{c}\text { PIAZZALUN } \\
\text { GA \& } \\
\text { LAMOUNIE } \\
\text { R } \\
(\mathbf{2 0 1 1})\end{array}$ & $\begin{array}{l}\text { Compreender, } \\
\text { sob a ótica } \\
\text { paterna e no } \\
\text { contexto } \\
\text { familiar, o papel } \\
\text { que o pai } \\
\text { exerce durante o } \\
\text { aleitamento } \\
\text { materno e os } \\
\text { fatores que } \\
\text { facilitam ou } \\
\text { dificultam sua } \\
\text { participação } \\
\text { nesse processo. }\end{array}$ & $\begin{array}{l}\text { Trata-se } \\
\text { abordagem } \\
\text { qualitativa realizada } \\
\text { em } \\
\text { Hospital Amigo da } \\
\text { Criança, Belo } \\
\text { Horizonte/MG/Brasil. } \\
\text { Foram investigados } \\
12 \text { homens. }\end{array}$ & Qualitativa & $\begin{array}{l}\text { A chegada do filho promove } \\
\text { a transformação do casal em } \\
\text { família nuclear, com a } \\
\text { emergência de novas } \\
\text { responsabilidades. } \\
\text { colaboração em tarefas de } \\
\text { cuidador do bebê permite } \\
\text { não só os sentimentos } \\
\text { tradicionais da paternidade, } \\
\text { mas de participante ativo } \\
\text { (não apenas observador) das } \\
\text { relações familiares. }\end{array}$ & $\begin{array}{l}\text { L } \\
\text { I } \\
\text { L } \\
\text { A } \\
\text { C } \\
\text { S }\end{array}$ \\
\hline $\begin{array}{l}\text { REMPEL \& } \\
\text { REMPEL } \\
\text { (2011) }\end{array}$ & $\begin{array}{lr}\text { Investigar } & \text { as } \\
\text { percepções } & \text { dos } \\
\text { pais sobre } & \text { seus } \\
\text { papéis } & \text { como } \\
\text { membros } & \text { da } \\
\text { família } & \text { que } \\
\text { amamenta. } & \end{array}$ & $\begin{array}{l}\text { Recrutam } 21 \text { casais } \\
\text { para participarem de } \\
\text { um estudo sobre o pai } \\
\text { na família de } \\
\text { amamentação, por } \\
\text { meio de folhetos em } \\
\text { centros de recursos } \\
\text { parentais provinciais } \\
\text { em duas regiões de } \\
\text { Ontário, Canadá, e } \\
\text { por meio de convites } \\
\text { pessoais em grupos } \\
\text { de brincadeiras mãe- } \\
\text { bebê e grupos de pais } \\
\text { oferecidos pela } \\
\text { Centros. }\end{array}$ & Qualitativa & $\begin{array}{l}\text { Os pais identificaram seus } \\
\text { papéis únicos como membros } \\
\text { da equipe, garantindo que } \\
\text { seus bebês recebessem os } \\
\text { benefícios da amamentação. } \\
\text { O principal papel do pai era } \\
\text { apoiar o aleitamento materno } \\
\text { tornando-se mais experiente } \\
\text { em aleitamento materno, } \\
\text { usando seu conhecimento } \\
\text { para encorajar e auxiliar as } \\
\text { mães na amamentação, } \\
\text { valorizando as mães que } \\
\text { amamentam } \\
\text { compartilhando o trabalho } \\
\text { doméstico e o cuidado das } \\
\text { crianças. }\end{array}$ & $\begin{array}{l}\text { C } \\
\text { I } \\
\text { N } \\
\text { A } \\
\text { H } \\
\text { L }\end{array}$ \\
\hline $\begin{array}{l}\text { MITCHELL- } \\
\text { BOX \& } \\
\text { BRAUN } \\
\text { (2012) }\end{array}$ & $\begin{array}{l}\text { Explorar as } \\
\text { percepções do } \\
\text { parceiro sobre o } \\
\text { aleitamento } \\
\text { materno para } \\
\text { formular o } \\
\text { desenvolvimento } \\
\text { de intervenções } \\
\text { para aumentar o } \\
\text { apoio ao } \\
\text { aleitamento } \\
\text { materno. }\end{array}$ & $\begin{array}{l}14 \text { participantes do } \\
\text { sexo masculino de } \\
\text { gestantes de baixa } \\
\text { renda ou novas mães. } \\
\text { Métodos: Atitudes, } \\
\text { conhecimentos } \\
\text { sentimentos de } \\
\text { parceiros do sexo } \\
\text { masculino foram } \\
\text { coletados por meio de } \\
\text { entrevistas privadas. } \\
\text { Os dados foram } \\
\text { analisados usando } \\
\text { métodos da teoria } \\
\text { fundamentada. }\end{array}$ & Qualitativa & 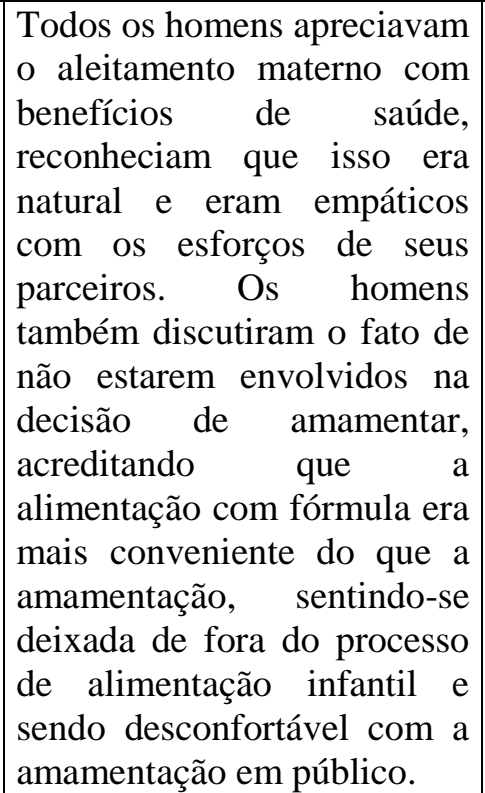 & $\begin{array}{c}\mathbf{P} \\
\mathbf{U} \\
\mathbf{B} \\
\mathbf{M} \\
\mathbf{E} \\
\mathbf{D}\end{array}$ \\
\hline
\end{tabular}




\begin{tabular}{|c|c|c|c|c|c|}
\hline $\begin{array}{l}\text { CHEZEM } \\
\text { (2012) }\end{array}$ & $\begin{array}{lr}\text { Descrever } & \text { as } \\
\text { atitudes } & \\
\text { maternas } & \text { e } \\
\text { paternas } & \text { em } \\
\text { relação } & \text { à } \\
\text { amamentação } & \\
\text { entre casais } & \text { que } \\
\text { planejam } & \text { o } \\
\text { aleitamento } & \\
\text { materno } & \\
\text { exclusivo } & \text { e } \\
\text { aqueles } & \text { que } \\
\text { planejam } & \\
\text { alimentação } & \\
\text { mista } & \text { e } \\
\text { comparar } & \text { as } \\
\text { previsões } & \\
\text { maternas } & \text { de } \\
\text { atitudes paternas } \\
\text { com as atitudes } \\
\text { paternas reais. }\end{array}$ & $\begin{array}{l}71 \text { pais com intenção } \\
\text { de } \text { amamentar } \\
\text { recrutados }\end{array}$ & Quantitativa & $\begin{array}{l}\text { Entre os pais, aqueles que } \\
\text { planejam o aleitamento } \\
\text { materno } \\
\text { expressaram atitudes mais } \\
\text { favoráveis relacionadas à } \\
\text { naturalidade }(p=0,009) \text { e } \\
\text { proximidade }(p=0,036) \text { do } \\
\text { que seus pares de } \\
\text { aleitamento misto. }\end{array}$ & $\begin{array}{l}\mathbf{P} \\
\mathbf{U} \\
\mathbf{B} \\
\mathbf{M} \\
\mathbf{E} \\
\mathbf{D}\end{array}$ \\
\hline $\begin{array}{c}\text { JACOB } \\
\& \text { SUJATHA } \\
\text { (2013) }\end{array}$ & $\begin{array}{l}\text { Avaliar } \\
\text { conhecimento } \\
\text { a atitude dos } \\
\text { pais em relação } \\
\text { à amamentação. }\end{array}$ & $\begin{array}{lr}\text { Utilizou-se } & \\
\text { questionário } & \text { de } \\
\text { conhecimento } & \text { sobre } \\
\text { amamentação } & \text { e } \\
\text { escala de atitude de } \\
\text { amamentação } & \text { com } \\
200 \text { pais. }\end{array}$ & Quantitativa & 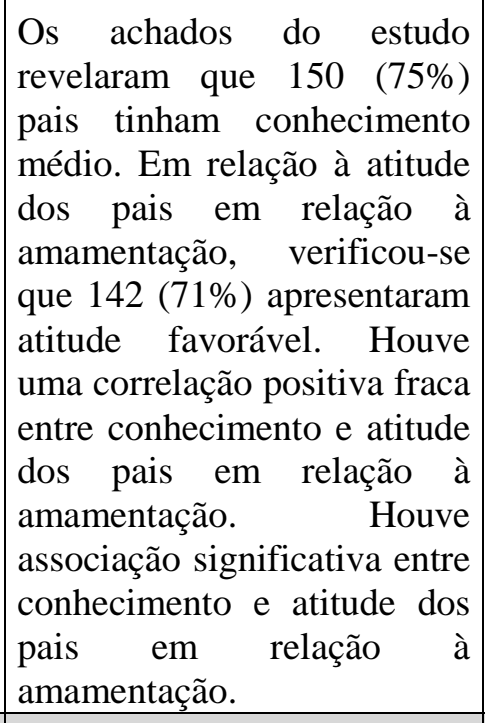 & $\begin{array}{l}\text { C } \\
\text { I } \\
\text { N } \\
\text { A } \\
\text { H } \\
\text { L }\end{array}$ \\
\hline $\begin{array}{l}\text { TAS-PINAR, } \\
\text { et al (2013) }\end{array}$ & \begin{tabular}{|lr} 
Determinar & a \\
extensão & do \\
conhecimento & \\
que pais & de \\
recém-nascidos \\
têm & sobre \\
aleitamento & \\
materno & e \\
lactação & e \\
examinar & suas \\
atitudes & em \\
relação & à \\
amamentação. &
\end{tabular} & \begin{tabular}{|lrr} 
Estudo & descritivo & e \\
transversal. & \\
Participantes: & 203 \\
pais & de & recém- \\
nascidos. & Os & dados \\
foram & coletados & com \\
um & questionário & que \\
foi & preparado & pelos \\
pesquisadores & após \\
uma & revisão & da \\
literatura. Os & achados \\
descritivos & básicos \\
foram & estabelecidos
\end{tabular} & Quantitativa & $\begin{array}{l}\text { Embora a grande maioria dos } \\
\text { participantes }(92,1 \%) \text { tenha } \\
\text { expressado o desejo de ter } \\
\text { seus filhos amamentados, } \\
\text { constatou-se que apenas } \\
58,6 \% \text { discutiram isso com } \\
\text { seus parceiros. Descobriu-se } \\
\text { que } 88,7 \% \text { dos pais estavam } \\
\text { felizes em ajudar nas tarefas } \\
\text { domésticas para que suas } \\
\text { esposas pudessem } \\
\text { amamentar, enquanto que } \\
57,6 \% \text { declararam que a }\end{array}$ & $\begin{array}{l}\text { C } \\
\text { I } \\
\text { N } \\
\text { A } \\
\text { H } \\
\text { L }\end{array}$ \\
\hline
\end{tabular}




\begin{tabular}{|c|c|c|c|c|c|}
\hline & & $\begin{array}{lrr}\text { usando o } & \text { SPSS } \\
\text { (Statistical } & \text { Package } \\
\text { for the } & \text { Social } \\
\text { Sciences). } & \end{array}$ & & $\begin{array}{l}\text { amamentação seria } \\
\text { psicologicamente benéfica } \\
\text { tanto para a mãe quanto para } \\
\text { o bebê. Aproximadamente } \\
\text { metade dos sujeitos do } \\
\text { estudo }(48,8 \%) \text { manifestaram } \\
\text { interesse em participar de um } \\
\text { programa educacional sobre } \\
\text { aleitamento materno para os } \\
\text { pais. }\end{array}$ & \\
\hline $\begin{array}{l}\text { ITO et al } \\
\text { (2013) }\end{array}$ & $\begin{array}{lr}\text { Analisar } & \text { a } \\
\text { associação do } & \text { do } \\
\text { envolvimento } & \\
\text { paterno r no } \\
\text { cuidado infantil } \\
\text { e no trabalho } \\
\text { doméstico com o } \\
\text { aleitamento } \\
\text { materno rr } \\
\text { exclusivo nos } \\
\text { primeiros ra } \\
\text { meses de vida. }\end{array}$ & 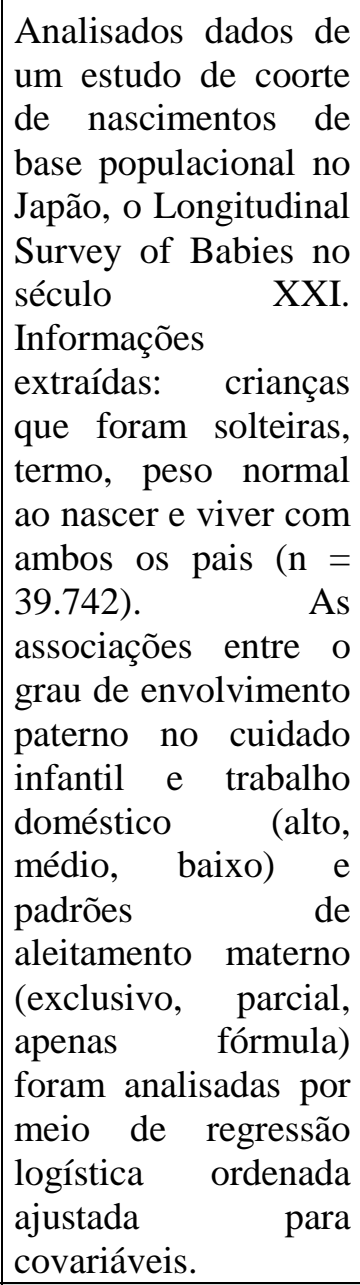 & Quantitativa & $\begin{array}{l}\text { Em comparação com o baixo } \\
\text { nível de cuidados paternos } \\
\text { infantis, os bebês dos grupos } \\
\text { intermediário e alto tiveram } \\
\text { uma probabilidade } \\
\text { significativamente menor de } \\
\text { serem amamentados (odds } \\
\text { ratio ajustada: } 0,90 \text {, intervalo } \\
\text { de confiança de 95\% [IC], } \\
0,84-0,97 \text {; e } 0,73 \text {, 95\% CI, } \\
0,67-0,79 \text {, respectivamente). } \\
\text { Em contraste, a quantidade } \\
\text { de tarefas domésticas } \\
\text { realizadas pelos pais não foi } \\
\text { associada ao padrão de } \\
\text { amamentação. A ansiedade } \\
\text { materna sobre a educação } \\
\text { das crianças não atenuou a } \\
\text { associação entre o cuidado } \\
\text { do bebê paterno e a } \\
\text { amamentação. }\end{array}$ & $\begin{array}{l}\mathbf{C} \\
\mathbf{I} \\
\mathbf{N} \\
\mathbf{A} \\
\mathbf{H} \\
\mathbf{L}\end{array}$ \\
\hline $\begin{array}{c}\text { BROWN \& } \\
\text { DAVIES } \\
(\mathbf{2 0 1 4 )}\end{array}$ & \begin{tabular}{|lr} 
Explorar o papel \\
do pai no apoio \\
à & amamentação \\
e, & mais \\
importante, & a \\
informação & e \\
orientação & que \\
ele & pode \\
precisar. &
\end{tabular} & $\begin{array}{lr}\text { 117 } & \text { homens em que a } \\
\text { parceira havia dado à } \\
\text { luz nos } 2 & \text { anos } \\
\text { anteriores e iniciado a } \\
\text { amamentação } & \text { no } \\
\text { nascimento. } & \\
\text { Completaram } & \text { um } \\
\text { questionário } & \text { aberto } \\
\text { explorando } & \text { suas } \\
\text { experiências } & \text { de } \\
\text { amamentação, } & \text { as } \\
\text { informações } & \text { e } \\
\text { apoio que receberam }\end{array}$ & Qualitativa & $\begin{array}{l}\text { Os pais eram encorajadores } \\
\text { em relação à amamentação e } \\
\text { queriam ser capazes de } \\
\text { sustentar sua parceira. No } \\
\text { entanto, eles geralmente não } \\
\text { conseguem manter relações } \\
\text { de amamentação e não têm } \\
\text { apoio suficiente para sua } \\
\text { parceira nesse momento. }\end{array}$ & $\begin{array}{l}\text { P } \\
\text { U } \\
\text { B } \\
\text { M } \\
\text { E } \\
\text { D }\end{array}$ \\
\hline
\end{tabular}




\begin{tabular}{|c|c|c|c|c|c|}
\hline & & $\begin{array}{l}\text { e suas ideias para a } \\
\text { futura educação e } \\
\text { promoção do } \\
\text { aleitamento materno } \\
\text { voltadas para pais e } \\
\text { famílias. }\end{array}$ & & & \\
\hline $\begin{array}{l}\text { LACERDA, } \\
\text { et al (2014) }\end{array}$ & $\begin{array}{l}\text { Compreender as } \\
\text { formas pelas } \\
\text { quais os pais } \\
\text { adolescentes } \\
\text { participam do } \\
\text { processo de } \\
\text { amamentação no } \\
\text { ambienter } \\
\text { familiar no } \\
\text { Nordeste r do } \\
\text { Brasil. }\end{array}$ & $\begin{array}{l}\text { Descritivo } \\
\text { exploratório, com } 10 \\
\text { casais de crianças de } \\
6 \text { a } 8 \text { meses de idade, } \\
\text { residentes em uma } \\
\text { única comunidade do } \\
\text { Recife, Pernambuco, } \\
\text { Brasil. Entrevistas } \\
\text { semiestruturadas. Os } \\
\text { dados foram } \\
\text { analisados por meio } \\
\text { da análise de } \\
\text { conteúdo temática e } \\
\text { interpretados sob o } \\
\text { referencial teórico de } \\
\text { ser pai adolescente no } \\
\text { contexto } \\
\text { amamentação. da }\end{array}$ & Qualitativa & 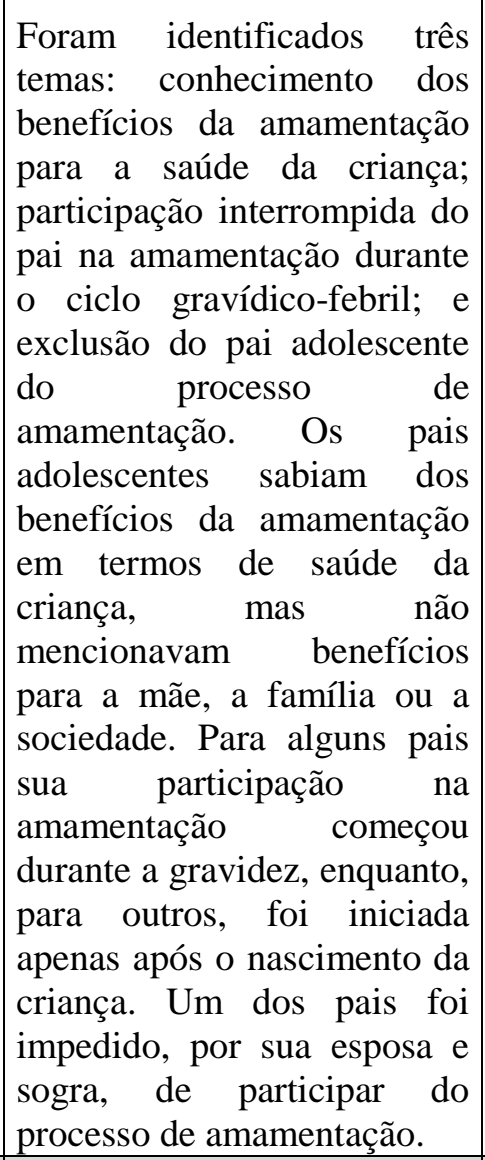 & $\begin{array}{l}\text { C } \\
\text { I } \\
N \\
\text { A } \\
\text { H } \\
\text { L }\end{array}$ \\
\hline $\begin{array}{l}\text { EMMOTT \& } \\
\text { MACE } \\
\text { (2015) }\end{array}$ & $\begin{array}{c}\text { Explorar as } \\
\text { associações } \\
\text { entre os } \\
\text { diferentes tipos } \\
\text { de apoio social } \\
\text { que as mães } \\
\text { recebem dos } \\
\text { pais / avós e a } \\
\text { amamentação no } \\
\text { UK Millennium } \\
\text { Cohort Study }\end{array}$ & 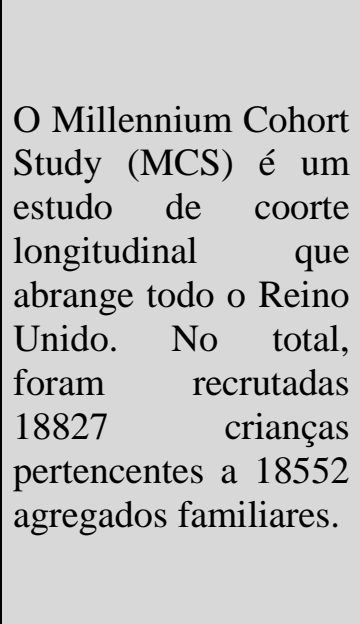 & Quantitativa & $\begin{array}{l}\text { O contato frequente com a } \\
\text { avó e o envolvimento dos } \\
\text { pais com os pais está } \\
\text { associado a níveis mais } \\
\text { baixos de amamentação, } \\
\text { sugerindo uma relação } \\
\text { negativa entre o apoio } \\
\text { prático a amamentação. Em } \\
\text { contraste, a presença do pai, } \\
\text { potencialmente capturando } \\
\text { apoio emocional, está } \\
\text { associada a uma maior } \\
\text { iniciação ao aleitamento } \\
\text { materno. aratar }\end{array}$ & $\begin{array}{c}\mathbf{P} \\
\mathbf{U} \\
\mathbf{B} \\
\mathbf{M} \\
\mathbf{E} \\
\mathbf{D}\end{array}$ \\
\hline
\end{tabular}




\begin{tabular}{|c|c|c|c|c|c|}
\hline $\begin{array}{l}\text { MATOS, } \\
\text { et al } \\
(\mathbf{2 0 1 5 )}\end{array}$ & $\begin{array}{l}\text { Analisar a } \\
\text { participação do } \\
\text { pai durante o } \\
\text { período de } \\
\text { amamentação, } \\
\text { bem como sua } \\
\text { percepção sobre } \\
\text { a importância do } \\
\text { apoio nessa fase. }\end{array}$ & $\begin{array}{l}\text { Estudo descritivo } \\
\text { transversal, no qual } \\
\text { participaram } 20 \text { pais } \\
\text { de crianças entre os } \\
\text { três meses de vida e } \\
\text { um ano de idade que } \\
\text { vivenciaram } \\
\text { experiência } \\
\text { amamentação da } \\
\text { filhos. A análise dos } \\
\text { dados fundamentou- } \\
\text { se na Análise de } \\
\text { Conteúdo Temática. }\end{array}$ & Qualitativa & $\begin{array}{l}\text { Foram destacadas } \\
\text { seguintes as } \\
\text { registro: cuidados com o } \\
\text { bebê, cuidados com a casa e } \\
\text { cuidados com a alimentação } \\
\text { da mãe. No tocante ao } \\
\text { conhecimento sobre o o } \\
\text { aleitamento } \\
\text { percebemos as unidades de } \\
\text { registro: promoção da saúde } \\
\text { e prevenção de doenças, } \\
\text { proporciona } \\
\text { mãe/filho, promove melhor } \\
\text { desenvolvimento } \\
\text { crescimento. }\end{array}$ & $\begin{array}{l}\text { C } \\
\text { I } \\
\text { N } \\
\text { A } \\
\text { H } \\
\text { L }\end{array}$ \\
\hline $\begin{array}{c}\text { AZEVEDO, } \\
\text { et al } \\
(\mathbf{2 0 1 6 )}\end{array}$ & $\begin{array}{l}\text { Identificar } \\
\text { conhecimento } \\
\text { do pai sobre o } \\
\text { aleitamento } \\
\text { materno. }\end{array}$ & $\begin{array}{l}\text { Trata-se de um } \\
\text { estudo exploratório e } \\
\text { descritivo, realizado } \\
\text { em uma Unidade de } \\
\text { Saúde da Família, em } \\
\text { um município do } \\
\text { interior do Rio } \\
\text { Grande do Norte, } \\
\text { Brasil. Os dados } \\
\text { foram obtidos por } \\
\text { meio de entrevista } \\
\text { semiestruturada. A } \\
\text { população } \\
\text { composta por } 15 \text { pais, } \\
\text { com idade acima dos } \\
18 \text { anos. As } \\
\text { informações foram } \\
\text { organizadas segundo } \\
\text { Bardin, dando origem } \\
\text { a duas categorias e } \\
\text { analisadas de acordo } \\
\text { com o Interacionismo } \\
\text { Simbólico. }\end{array}$ & Qualitativa & $\begin{array}{l}\text { A maioria dos entrevistados } \\
\text { tem conhecimento sobre o } \\
\text { assunto e reconhece os } \\
\text { benefícios da amamentação, } \\
\text { desta forma conseguem } \\
\text { incentivar suas esposas com } \\
\text { vistas ao aleitamento } \\
\text { materno exclusivo. }\end{array}$ & $\begin{array}{l}\text { I } \\
\text { L }\end{array}$ \\
\hline $\begin{array}{l}\text { DENOUAL, } \\
\text { et al (2016) }\end{array}$ & $\begin{array}{l}\text { Analisar as } \\
\text { crenças sociais, } \\
\text { representações e } \\
\text { vivências de pais } \\
\text { de recém- } \\
\text { nascidos pré- } \\
\text { termo (RNs) em } \\
\text { relação r ao } \\
\text { aleitamento } \\
\text { materno. }\end{array}$ & $\begin{array}{lr}\text { Entrevista } & \text { com } \\
\text { análise } & \text { de } \\
\text { transcrições } & \\
\text { utilizando o software } \\
\text { Alceste. } & \text { Local: } \\
\text { Unidade de terapia } \\
\text { intensiva neonatal de } \\
\text { um } r \text { hospital } \\
\text { universitário terciário } \\
\text { (UTIN) na França. } \\
\text { Participantes: } & 20 \text { pais } \\
\text { de RNs pré-termo } \\
\text { internados em uma } \\
\text { UTIN. }\end{array}$ & Qualitativa & $\begin{array}{l}\text { A análise demonstrou que os } \\
\text { pais eram sensíveis a } \\
\text { argumentos relacionados aos } \\
\text { benefícios para a saúde do } \\
\text { leite humano. Eles também } \\
\text { mencionaram ramo } \\
\text { poderiam comuinamente } \\
\text { ajudar seus parceiros durante } \\
\text { a amamentação. }\end{array}$ & $\begin{array}{l}\text { P } \\
\text { U } \\
\text { B } \\
\text { M } \\
\text { E } \\
\text { D }\end{array}$ \\
\hline
\end{tabular}




\begin{tabular}{|c|c|c|c|c|c|}
\hline $\begin{array}{l}\text { BENNET } \\
\mathrm{T} \text {, et al } \\
\text { (2016) }\end{array}$ & $\begin{array}{lr}\text { Investigar } & \text { a } \\
\text { relação } & \text { entre } \\
\text { pais } & \text { e } \\
\text { aleitamento } \\
\text { materno } & \text { na } \\
\text { Irlanda. } & \end{array}$ & $\begin{array}{l}\text { Questionário semi- } \\
\text { quantitativo } \\
\text { transversal com } \\
\text { perguntas fechadas e } \\
\text { abertas com } 1398 \\
\text { homens que tinham } \\
\text { parceira irlandês que } \\
\text { havia dado à luz } 4-7 \\
\text { meses antes. Os } \\
\text { dados das questões } \\
\text { fechadas r sobre } \\
\text { aleitamento materno } \\
\text { foram apresentados } \\
\text { utilizando } \\
\text { frequências } \\
\text { porcentagens } \\
\text { associadas. }\end{array}$ & Quantitativa & $\begin{array}{l}\text { Entre os pais, aqueles que } \\
\text { planejam o aleitamento } \\
\text { materno } \\
\text { expressaram atitudes mais } \\
\text { favoráveis relacionadas à } \\
\text { naturalidade }(\mathrm{p}=0,009) \text { e } \\
\text { proximidade }(\mathrm{p}=0,036) \text { do } \\
\text { que seus pares de } \\
\text { aleitamento misto. }\end{array}$ & $\begin{array}{c}\mathbf{C} \\
\mathbf{I} \\
\mathbf{N} \\
\mathbf{A} \\
\mathbf{H} \\
\mathbf{L}\end{array}$ \\
\hline $\begin{array}{c}\text { MONTIGNY, } \\
\text { et al (2018) }\end{array}$ & $\begin{array}{lr}\text { Identificar } & \text { as } \\
\text { percepções } & \text { dos } \\
\text { pais sobre } & \text { seu } \\
\text { papel } & \text { no } \\
\text { contexto } & \text { da } \\
\text { amamentação. }\end{array}$ & 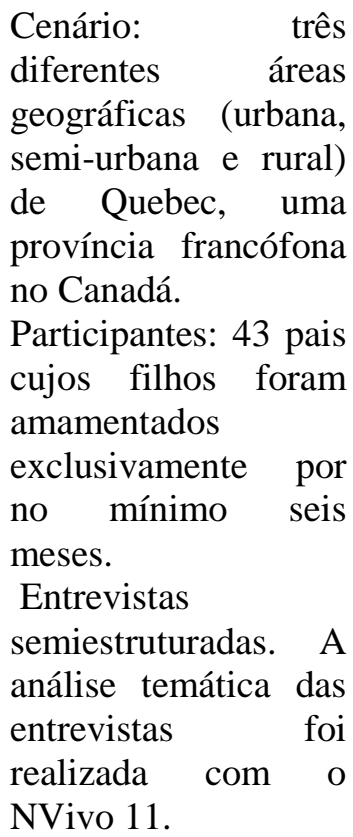 & Qualitativa & $\begin{array}{l}\text { Identificaram-se variações no } \\
\text { papel do pai durante a } \\
\text { amamentação, a saber: 1) } \\
\text { agir como parceiros na } \\
\text { tomada de decisão; 2) ser } \\
\text { responsável pelo } \\
\text { funcionamento familiar e 3) } \\
\text { fornecer apoio emocional à } \\
\text { mãe. Essas diferentes } \\
\text { variantes envolvem desafios } \\
\text { e tarefas. }\end{array}$ & $\begin{array}{l}\text { C } \\
\text { I } \\
\text { N } \\
\text { A } \\
\text { H } \\
\text { L }\end{array}$ \\
\hline
\end{tabular}

A partir da integração dos resultados dos estudos que compuseram a amostra desta revisão, identificaram-se dois eixos temáticos representativos dos conhecimentos e atitudes paternas em relação à amamentação, a saber: conhecimentos paternos em relação ao aleitamento materno: benefícios e desvantagens; e atitudes paternas frente à amamentação: enlaces entre desejos e impasses no apoio ao aleitamento materno. 
1. Conhecimentos paternos em relação ao aleitamento materno: benefícios e desvantagens

Do total de 16 artigos analisados nesta pesquisa, todos evidenciaram, em alguma medida, que os pais possuem conhecimento referente ao benefício da amamentação para o bebê, até mesmo em culturas como a japonesa, em que o pai exerce um papel mais secundário na construção da relação mãe/amamentação/bebê. Em contrapartida, os pais não apresentaram conhecimentos suficientes quanto aos benefícios da amamentação para a mulher/esposa.

Com relação aos conhecimentos paternos sobre a amamentação, as pesquisas desenvolvidas apresentam conclusões muito similares: os pais alegam não apresentar conhecimento adequado sobre o aleitamento materno, bem como não ter recebido orientações sobre o assunto durante o pré-natal ou ter recebido um conhecimento precário, gerando, como consequência, pouca participação e integração no processo de amamentação (PAULA et al, 2010; AZEVEDO et al, 2016; BENNETT et al, 2016; BROWN \& DAVIES,2014).

Os irlandeses demostraram a necessidade de compreender, além do básico da amamentação (posições adequadas, produção de leite), as maneiras de apoiar emocionalmente sua parceira no processo de amamentação. Verificou-se também que os pais revelaram o interesse em apoiar suas parceiras durante o período de amamentação, contudo, alegam falta de conhecimento, compreensão e habilidade para desenvolver esta tarefa; eles afirmam sentir falta de uma formação voltada especificamente para eles (BENNETT et al, 2016; BROWN \& DAVIES, 2014). Os japoneses, são completamente alheios a estes conhecimentos e não demonstram interesse no assunto (ITO et al, 2013). Os pais havaianos, embora considerem a amamentação como fundamental, não se sentem aptos a opinar sobre o tempo de durabilidade do processo de amamentação e acreditam ainda que fórmulas lácteas podem ser utilizadas, a qualquer momento, a depender das necessidades físicas e emocionais da mãe (MITCHELLBOX \& BRAUN, 2012). Os canadenses são bem participativos neste processo e demonstram interesse em participar de todo o processo alimentar do bebê. O artigo, porém, não aborda o tempo de amamentação exclusiva nesta cultura (MONTIGNY et al, 2018).

Quanto a temática de contribuição para benefícios financeiros, apenas nos artigos que tratam da visão dos irlandeses e dos havaianos sobre o aleitamento, é que se cogita a entrada da fórmula na alimentação dos bebês, contudo, o aspecto financeiro não é abordado em nenhum deles (BENNETT et al, 2016; MITCHELL-BOX \& BRAUN, 2012). 
Sobre as dificuldades associadas à amamentação para o pai, verificou-se que os pais havaianos reconhecem e são solidários com a rotina pesada da mãe, como sonos irregulares, problemas com amamentação em público. Os pais canadenses, evidenciaram que também se sentem importantes e partícipes nesta tarefa de tornar menos árdua e cansativa a função da mãe durante a amamentação (MITCHELL-BOX \& BRAUN, 2012; MONTIGNY et al, 2018).

As desvantagens da amamentação na percepção dos pais compreende mau-humor, estresse do casal, ciúmes da conexão entre mãe e bebê, liderança quanto a disputa de irmão pela atenção materna e perda da intimidade do casal (BENNETT et al, 2016). Sobre o fato da perda da intimidade do casal, segundo NUNES (2014), durante o processo de gravidez e puerpério envolvendo a amamentação, o homem também passa pela adaptação e descoberta do papel de pai, o que pode influenciar o processo íntimo sexual do casal. O enfermeiro deve ter como foco o companheiro/marido no processo do cuidar promover saúde harmoniosamente em todas as esferas de forma a evitar inseguranças e ansiedades.

2. Atitudes paternas frente à amamentação: enlaces entre desejos e impasses no apoio ao aleitamento materno

A literatura sobre amamentação, de uma maneira geral, trata exaustivamente da relação mãe-bebê. Mudanças gradativas nas sociedades, contudo, têm cobrado dos pais um papel mais ativo nesta tarefa. Dessa forma, pergunta-se: quais as atitudes dos pais frente à amamentação? COSTA (2007), em sua dissertação de mestrado, defende que

\begin{abstract}
Um homem só se torna pai (e constrói a identidade de pai) ao reconhecer em outrem a condição de filho, isto é, ao exercer um papel ativo em seu meio familiar e na sociedade, referendado pelo papel de outros entes sociais que o cercam. Em nossa cultura, as ideias de pai e paternidade parecem mesclar, formando um só corpo e referencial [...]Uma visão mais moderna da paternidade, em termos de atitude, exige um pai mais presente com envolvimento direto, acessível e mais responsável pela criação conjunta dos filhos (COSTA, 2007, pág. 09).
\end{abstract}

Nesta perspectiva, buscou-se analisar resultados de como essas atitudes paternas são manifestadas na prática da amamentação, considerando variáveis como sociedade e cultura.

Para iniciar as discussões, cabe ressaltar que o modelo familiar burguês, em meados do século XIX, era representado pela estrutura da mulher que deveria buscar proteção do marido e servir ao lar como mãe e boa esposa. Nesse modelo tradicional, o homem deveria dedicar-se a negócios externos de casa, ao mundo público, provendo dinheiro e segurança 
para sua família, não sendo responsável por atividades domésticas e muito menos cuidados diretos com seus filhos (CHECHI e HILLESHEIM, 2008).

Os modelos estão sempre em constante mutação, sendo possível verificar nesse contexto mudanças culturais relevantes no final dos anos 1960 e início de 1970. Com o novo modelo econômico industrial, movimentos feministas contribuíram para introdução das mulheres no mercado de trabalho e início de discussões sobre as diferenças de gêneros, de forma que as mulheres passaram a assumir novos papéis no contexto público para além do protagonismo no lar. Essas mudanças contribuíram lentamente para um novo olhar quanto ao papel do homem/pai no centro da família, que se insere também como cuidador principal do seu filho, modelo cada dia mais "naturalizado" em nossa cultura atual (TEYKAL e ROCHACOUTINHO, 2007).

Destaca-se uma transformação na participação do pai no contexto da amamentação que permitem identificar mudanças e, até mesmo, a construção do "novo pai", com a redefinição de seu papel. "Muitos dos pais expressaram interesse e satisfação em poder cuidar dos filhos e de ter participação mais efetiva na vida da família, papéis desejáveis do 'novo pai' " (PIAZZALUNGA \& LAMONIER, 201, p. 40). Apesar dessas mudanças positivas sobre as relações de gênero, alguns pais ainda possuem uma visão muito tradicional da divisão de tarefas e, ainda, consideram o aleitamento materno como função exclusiva da mulher, enquanto o homem desempenha o papel de mantenedor do lar, corroborando com as ideias patriarcais do século XIX.

Em uma amostra do presente estudo intitulado "The Breastfeeding Team: The Role of Involved Fathers in the Breastfeeding Family" os autores entrevistaram 21 pais canadenses de bebês lactentes com a finalidade de sondar quais os papéis desempenhados por esses pais no processo de amamentação. Os resultados mostraram que eles se viam com uma função secundária na amamentação; na "periferia" em relação à ligação com seus filhos. Contudo, em relação às atitudes, os participantes da pesquisa alegaram oferecer apoio direto e indireto às mães, incluindo incentivos verbais e não-verbais na continuação do aleitamento. Quanto mais experientes esses pais se tornavam, mais eles usavam esses conhecimentos para reforçar as decisões sobre a amamentação. Vale ressaltar, ainda, que esses pais compreendiam que os comportamentos de apoio eram ações importantes para eles mesmos e não vistos como atitudes compensatórias (REMPEL \& REMPEL, 2011) 
Quanto a pais adolescentes, estes corroboram com as ideias aqui já discutidas sobre a atitude dos pais frente à amamentação: ainda temos uma visão patriarcal da função do homem e da mulher frente à amamentação, contudo, novas práticas já estão emergindo na sociedade. Os autores consideram ainda a ideia de que a amamentação é uma decisão social e não apenas nutricional, isto é, "a educação de homens e mulheres pode influenciar a construção de novas práticas relacionadas ao aleitamento materno" (tradução livre).

Dessa forma, a educação pode ajudar a desenvolver um comportamento mais proativo de pais/homens no processo de aleitamento materno (LARCERDA et al, 2014). Seguindo esta linha de raciocínio de mudanças progressivas no cuidado paterno com a mãe e o bebê, a maioria dos pais ajudam a esposa com atividades do cotidiano, tais como: trocar a fralda, buscar a criança no berço durante a noite, fazer a comida, dentre outras. Essas atitudes, são imprescindíveis para manutenção da amamentação de forma a evitar desmame precoce (AZEVEDO et al, 2016).

Destaca-se a importância de se considerar as variáveis sociais e culturais para o processo de aleitamento como: educação do pai e do cônjuge, ocupação do pai, renda familiar mensal, número total de filhos, número de filhos abaixo de 3 anos e status socioeconômico (JACOB \& SUJATHA,2013; LARCERDA et al, 2014).

Na Turquia, os pais consideram importante a amamentação de seus bebês, contudo, eles não discutem esses sentimentos com suas esposas e têm um conhecimento limitado sobre lactação e amamentação. Os dados dessa pesquisa revelaram que 92,6\% dos homens declararam acompanhar suas esposas às consultas de pré-natal, todavia, apenas metade alegou ter conhecimentos sobre o aleitamento; desses, 46,7\% disseram ter obtido orientações de profissionais de saúde, um número considerado baixo. Assim como já discutido por outros autores, ainda ressalta-se a importância de fatores sociais e educacionais para uma visão favorável da amamentação (TAS-PINAR et al, 2013).

Já no Ceará, na cidade de Chorozinho, evidenciaram um aumento na qualidade da participação paterna no processo de acompanhamento da gestante até a amamentação. Os autores perceberam que os pais demonstraram um maior interesse em vivenciar todos os momentos da gestação, fato este que gera e fortalece vínculos entre pai/bebê. Contudo, a grande crítica feita por estes pais refere-se à falta de tempo devido o trabalho. Muitos alegam não ter participação mais ativa devido jornada de trabalho de 40h (MATOS et al,2015). 
Quando analisamos este fato, percebemos como o trabalho pode interferir na ajuda paterna em relação ao cuidado com a mulher e o bebê nos primeiros momentos. A legislação brasileira prevê apenas 5 dias de licença paternidade para trabalhadores, porém mudança atual na legislação aumentou esta licença para 20 dias, no caso de trabalhadores de empresas inscritas no Programa Empresa-Cidadã (Lei 13.257/16). Embora a prazo da licença tenha se estendido, sabe-se que este ainda é, por vezes, insuficiente para o processo de ajustamento de responsabilidades e laços afetivos entre mãe/pai. Os primeiros momentos são essenciais para o envolvimento emocional da tríade mãe/filho/pai.

Sobre o tempo de licença paternidade, dados divulgados pela revista FORBES BRASIL, em 2015, referentes aos países com maior tempo de licença paternidade, apontam o quanto o Brasil ainda precisa rever políticas que valorizem e favoreçam o desenvolvimento da parentalidade desde a primeira infância. Enquanto o Brasil conta com 5 a 20 dias de licença, a depender do regime de trabalho, países como a Coréia do Sul e Japão possuem, respectivamente, 52,6 e 52 semanas de licença, com salário médio equivalente a $31 \%$ do total na Coréia do Sul, e 58,4\%, no Japão. A Noruega destaca-se por proporcionar aos pais 14 semanas de licença com remuneração de $90,8 \%$ do salário.

Uma informação que nos chama atenção nesta pesquisa, refere-se ao tempo de licença paternidade no Japão, visto que estudos realizados apresentam informações alarmantes sobre a amamentação e as atitudes paternas neste país. No país, não há uma associação diretamente proporcional da amamentação com o auxílio pateno em tarefas domésticas. Os dados da revista FORBES são relevantes quando comparados com esta realidade, pois demonstram a postura cultural de uma sociedade fortemente patriarcal, mas que caminha para o reconhecimento da igualdade de gênero. Segundo o documento THE GLOBAL GENDER GAP REPORT (2013), o Japão ocupa, hoje, o $105^{\circ}$ lugar no ranking de igualdade de gênero. Avalia-se a necessidade de uma intervenção e de uma educação dos pais, promovida pelos profissionais da saúde, para o aumento das taxas de amamentação (ITO et al, 2013).

Nesta perspectiva, ressalta-se ainda que somente a dilação do prazo da licença paternidade sem uma consciência da importância da função e da responsabilidade dos pais neste momento, como já elencado acima por vários autores, tornará esta licença ineficiente e ineficaz, continuando a manter o padrão tradicional em que somente a mãe/mulher tem função com o recém-nascido. 
Embora a mãe tenha outros suportes, como a avó materna que tradicionalmente a auxilia neste primeiro momento, SILVA et al, (2012, p. 123) afirmam que "a presença do pai é o suporte de maior relevância para a amamentação na perspectiva materna". Desta forma, é preciso pensar em estratégias que possibilitem ao pai uma maior participação presencial neste momento crucial. Esta ideia é corroborada por MARQUES et al, (2015) que acreditam que o pai influi e contribui na decisão do processo de continuidade da amamentação.

Embora o papel do pai seja essencial no processo de aleitamento, como já discutido anteriormente, BRANDÃO et al, (2012), alerta também para a presença de avós, familiares e vizinhos como figuras imprescindíveis no processo de amamentação, pois fazem com que a mãe se sinta mais segura e acolhida.

A avó materna é, tradicionalmente, a pessoa que está mais vinculada com a mãe, que além de promover o seu conforto, responsabiliza-se também pelo bem-estar da mãe e do bebê. A avó é "herdeira de um processo cumulativo de conhecimentos advindos de sua vivência e experiências adquiridas ao longo dos anos, tornando-a valorizada e respeitada", contudo, verifica-se uma intervenção por parte das avós no processo de amamentação que pode fragilizar o aleitamento exclusivo, uma vez que tendem a persuadir as mães a oferecer outras fontes de alimentos aos bebês como, por exemplo, água e chás, atitudes reforçadas devido ao contexto histórico-cultural em que foram criadas. Neste contexto, um pai consciente pode evitar o desmame precoce do bebê ao apoiar e reforçar as atitudes da mãe na tentativa da continuidade do aleitamento exclusivo, como defendem SILVA et al, (2012) e MARQUES et al, (2015).

Ainda sobre o papel das avós, na amostra compondo este presente estudo intitulado "Practical Support from Fathers and Grandmothers Is Associated with Lower Levels of Breastfeeding in the UK Millennium Cohort Study", os autores confirmam que o contato frequente com as avós está associado a uma menor probabilidade de continuidade e interrupção da amamentação, enquanto que a presença do pai está associada a maior probabilidade de início e continuidade desta prática (EMMOTT \& MACE, 2015).

No artigo intitulado "The role of fathers during breastfeeding" realizou-se estudo com 43 pais de bebês amamentados exclusivamente, por no mínimo 6 meses, em diferentes regiões de Québec, Canadá, que tinha como objetivo compreender o papel dos pais na amamentação. Dentre as principais conclusões desta pesquisa, destaca-se a percepção desses pais com um papel muito mais complexo do que o comumente designado a eles. Os pais se viam como 
partes interessadas na tomada de decisões relacionadas à maneira como seu filho era alimentado e reagiam ao desequilíbrio criado pela falta/ausência da amamentação (MONTIGNY et al, 2018).

Verificou-se que os pais repensaram suas funções e comportamentos dentro da família. O apoio dado às mães e filhos é visto por eles como obrigações pertinentes a sua nova condição a fim de prover um ambiente adequado para o aleitamento materno, bem como para facilitar a vida da lactante. Executar essas tarefas, além de contribuir para a experiência da amamentação, também ajudou esses pais a se sentirem úteis e a desenvolver um senso de competência, bem como possibilitou a eles estreitar os laços com seus filhos (MONTIGNY et al, 2018; REMPEL \& REMPEL, 2011)

Neste presente estudo, notou-se um comportamento que merece uma pesquisa própria: a vergonha das mães em amamentar seus filhos em público. Na Irlanda, a cultura do uso de fórmulas infantis perpassam gerações. Além do mais, restrições sociais e culturais ainda prejudicam a amamentação em público. Já no Havaí, embora os pais considerem a amamentação importante, os homens não se sentem confortáveis com a amamentação em público, sobretudo, se tratando de suas companheiras (BENNETT et al, 2016; MITCHELLBOX \& BRAUN, 2012).

GREENE et al (2003 apud BENNETT et al, 2016) afirmam que reações negativas a práticas desconhecidas são esperadas, como no caso da amamentação em público em sociedades onde tal prática não é popular; os autores ressaltam, entretanto, que tais reações geralmente se tornam mais positivas com o aumento da familiaridade com essas práticas, ressaltando a importância do trabalho de conscientização de toda a sociedade da importância da amamentação.

Os programas de promoção e educação do aleitamento materno têm, tradicionalmente, como alvo somente as mães, contudo, há fortes evidências para apoiar a inclusão dos pais nesses programas, uma vez que atitudes paternas negativas podem ser decisivas na amamentação exclusiva do bebê conforme os dados da pesquisa sugerem (CHEZEM, 2012).

O estudo realizado no Havaí demonstrou resultados semelhantes aos discutidos até o momento sobre as atitudes dos pais. Todavia, nesta pesquisa destaca-se um ponto não colocado nos demais artigos analisados nesta pesquisa: os pais havaianos consideram a alimentação com fórmula como uma maneira conveniente do parceiro interagir com o bebê e 
reduzir o estresse e o cansaço da mãe. Esses pais, embora desejassem se envolver ativamente na amamentação, consideram que cabe a mulher decidir o momento de suspender o aleitamento (MITCHELL-BOX \& BRAUN, 2012).

PAULA et al, (2010) reforça que cabe aos profissionais de saúde, com destaque ao enfermeiro, promover atividades integradoras. Os autores destacam ainda que os pais possuem pouco conhecimento sobre os benefícios do aleitamento materno para a criança e para a mãe e que

\footnotetext{
isso reforça a necessidade de implementação de ações de saúde, pois, se o pai conhecesse os benefícios biológicos, econômicos e psicológicos para o filho e toda a família provavelmente seria grande parceiro nesse processo, incentivando e contribuindo com o aleitamento de seu filho (PAULA et al, 2010, pág. 6).
}

Dessa forma, formações adequadas a esta temática devem atingir os profissionais de saúde que fazem parte principal da promoção da saúde, visando mudanças futuras do quadro, já que a capacitação desses profissionais ainda não é suficiente; há muito foco na técnica de amamentação e grande negligência em relação aos aspectos psicológicos, culturais e sociais dos pais envolvidos nesse processo. Portanto, está em tempo de haver maior publicação de estudos que objetivem a mudança educacional do quadro (SILVA et al, 2012; ITO et al, 2013).

\section{CONSIDERAÇÕES FINAIS}

Por fim, podemos concluir que embora tenha havido um avanço significativo no papel do pai frente à amamentação, ainda há muito a caminhar para a igualdade de gênero nos papeis do homem e da mulher nos cuidados com bebê. Alguns países, como o Canadá e a Inglaterra, parecem estar à frente no que concerne à consciência do pai na tarefa da amamentação.

Os resultados, de maneira geral, mostraram que os pais estão engajados e solícitos à promoção do aleitamento materno, todavia, alegam falta de conhecimento sobre várias abordagens deste assunto. Por isso, cabe, agora, ao profissional de saúde que lida diretamente com a realização dos pré-natais, consultas de crescimento e desenvolvimento, acompanhamento de aleitamento, dentre outros, desempenhar um papel mais incisivo de 
conscientização para a inclusão dos pais nas obrigações e nos cuidados deste com a mãe e o bebê. 


\section{REFERÊNCIAS:}

BRANDÃO, Erlayne Camapum et al. Caracterização da comunicação no aconselhamento em amamentação. Revista Eletrônica de Enfermagem, v. 14, n. 2, p. 355-65, 2012.

BRASIL. Ministério da Saúde. Saúde da criança: Aleitamento Materno e Alimentação Complementar. Brasília, DF, 2015.

BRASIL. Constituição (2005). Lei $\mathrm{n}^{\circ}$ LEI No 11.108, de 7 de abril de 2005. Altera a lei $n^{o}$ 8.080, de 19 de setembro de 1990, para garantir às parturientes o direito à presença de acompanhante durante o trabalho de parto, parto e pós-parto imediato, no âmbito do sistema único de saúde - SUS. Título II "do Sistema Único de Saúde". Brasília, DF, 7 maio 2005. Disponível em: <http://www.planalto.gov.br/ccivil_03/_Ato20042006/2005/Lei/L11108.htm>. Acesso em: 28 maio 2017.

BRASIL. Ministério da Saúde. Disponível em: <http://portalms.saude.gov.br/saude-paravoce/saude-da-crianca/aleitamento-materno>. Acesso em:_ 5 de mai.2018.

COSTA, Cleise dos Reis. Representação do papel do pai no aleitamento materno. Porto: Faculdade de Ciências da Nutrição e Alimentação da Universidade do Porto / Nutrição Clínica, 2007.

CHECHI, Pascale; HILLESHEIM, Betina. Paternidade e mídia. Barbarói, n. 28, p. 89, 2008.

DA SILVA, Priscila Palma et al. A percepção das mães sobre o apoio paterno\&; influência na duração do aleitamento materno; La percepción de las madres sobre el apoyo paterno\&58; influencia en la duración de la lactancia materna; The maternal perception on paternal support\&; influence on the duration of breastfeeding. Revista Paulista de Pediatria, v. 30, n. 3, p. 306-313, 2012.

DE SOUZA, Marcela Tavares; DA SILVA, Michelly Dias; DE CARVALHO, Rachel. Revisão integrativa: o que é e como fazer. Einstein, v. 8, n. 1 Pt 1, p. 102-6, 2010.

DE OLIVEIRA, Camila Martins et al. Promoção do Aleitamento Materno: intervenção educativa no âmbito da Estratégia de Saúde da Família. Enfermagem Revista, v. 20, n. 2, p. 99-108, 2017. 
FERRAZ, L.; OLIVEIRA, P. P. de; ANTONIOLLI, M. A.; BENEDETT, A.; BOSSETTI, V.; ALMEIDA, K. de. Opinião de mulheres sobre a participação do pai no aleitamento materno. Arq. Cienc. Saúde UNIPAR, Umuarama, v. 20, n. 2, p, 95-99, maio/ago. 2016.

FRIGERI, Mônica; MONTEIRO, Marko Synésio Alves. Qualis Periódicos: indicador da política científica no Brasil?. Estudos de Sociologia, v. 19, n. 37, 2015.

ITO, Jun; FUJIWARA, Takeo; BARR, Ronald G. Is paternal infant care associated with breastfeeding? A population-based study in Japan. Journal of human lactation, v. 29, n. 4, p. 491-499, 2013.

LACERDA, Maria Ribeiro; LABRONICI, Liliana Maria. Papel social e paradigmas da pesquisa qualitativa de enfermagem. Revista Brasileira de Enfermagem, v. 64, n. 2, 2011.

LIMA, Janete Pereira; DE OLIVEIRA CAZOLA, Luiza Helena; PÍCOLI, Renata Palópoli. A participação do pai no processo de amamentação. Cogitare Enfermagem, v. 22, n. 1, 2017.

MARQUES ES, Cotta RM, MAGALHÃES KA, SANT'ANA LF, GOMES AP, SIQUEIRABatista R. The influence of the social net of lactating mothers in the breastfeeding: the strategic role of the relatives and professionals of health. Cienc Saude Colet 2010;15 (Suppl 1):1391-400.

MENDES, KDS, Silveira, RCCP, Galvão CM. Revisão integrativa: método de pesquisa para a incorporação de evidências na saúde e na enfermagem. Texto \& contexto enferm. 2008;17(4): 758-64.

MCCARTHY, Niall. 15 países com maior tempo de licença paternidade. Revista FORBES Brasil. 2015. Disponível em: <http://forbes.uol.com.br/listas/2015/08/15-paises-com-maiortempo-de-licenca-paternidade/\#foto8>. Acesso em: 16 de jun.2018.

NUNES, Débora Fernanda. As competências e o percurso: a sexualidade no eixo promotor da intimidade do casal, no processo de maternidade. 2014. Tese de Doutorado.

PETITO, Anamaria Donato Castro et al. A importância da participação do pai no ciclo gravídico puerperal: uma revisão bibliográfica. REFACER-Revista Eletrônica da Faculdade de Ceres, v. 4, n. 1, 2015.

PIAZZALUNGA, Cleise dos Reis Costa; LAMOUNIER, Joel Alves. O contexto atual do pai na amamentação: uma abordagem qualitativa. 2011: 133-141. 
SHERRIFF, Nigel; HALL, Valerie; PANTON, Christina. Engaging and supporting fathers to promote breast feeding: A concept analysis. Midwifery, v. 30, n. 6, p. 667-677, 2014.

SILVA, Bruna Turaça; SANTIAGO, Luciano Borges; LAMONIER, Joel Alves. Apoio paterno ao aleitamento materno: uma revisão integrativa. Revista Paulista de Pediatria, v. 30, n. 1, p. 122-130, 2012.

TEYKAL, Carolina Macedo; ROCHA-COUTINHO, Maria Lúcia. O homem atual e a inserção da mulher no mercado de trabalho. Psico, v. 38, n. 3, 2007.

The Global Gender Gap Report. 2013. Disponível em: <http://www3.weforum.org/docs/WEF_GenderGap_Report_2013.pdf >. Acesso em: 16 de jun.2018. 